\title{
Article \\ Intelligent Vehicle Scheduling and Routing for a Chain of Retail Stores: A Case Study of Dhaka, Bangladesh
}

\author{
M. Azizur Rahman ${ }^{1, *}{ }^{\mathbb{C}}$, Al-Amin Hossain ${ }^{1}$, Binoy Debnath ${ }^{1}$, Zinnat Mahmud Zefat ${ }^{1}$, \\ Mohammad Sarwar Morshed ${ }^{1}$ (D) and Ziaul Haq Adnan ${ }^{2}$ (D) \\ 1 Department of Mechanical and Production Engineering, Ahsanullah University of Science and Technology, \\ Dhaka 1208, Bangladesh; alaminipe087@gmail.com (A.-A.H.); binoydebnath15@gmail.com (B.D.); \\ zefatmahmud@gmail.com (Z.M.Z.); m.morshed.mpe@aust.edu (M.S.M.) \\ 2 Department of Management, North South University, Dhaka 1229, Bangladesh; ziaul.adnan@northsouth.edu \\ * Correspondence: aziz.mpe@aust.edu or azizur777@gmail.com
}

check for updates

Citation: Rahman, M.A.; Hossain, A.-A.; Debnath, B.; Zefat, Z.M.;

Morshed, M.S.; Adnan, Z.H.

Intelligent Vehicle Scheduling and Routing for a Chain of Retail Stores: A Case Study of Dhaka, Bangladesh. Logistics 2021, 5, 63. https://doi.org/ $10.3390 /$ logistics 5030063

Academic Editors: EunSu Lee,

Yongjang Kwon, Melanie McDonald and Yong-Shin Park

Received: 24 June 2021

Accepted: 9 August 2021

Published: 14 September 2021

Publisher's Note: MDPI stays neutral with regard to jurisdictional claims in published maps and institutional affiliations.

Copyright: (c) 2021 by the authors. Licensee MDPI, Basel, Switzerland. This article is an open access article distributed under the terms and conditions of the Creative Commons Attribution (CC BY) license (https:// creativecommons.org/licenses/by/ $4.0 /)$.

\begin{abstract}
Background: Retail chains aim to maintain a competitive advantage by ensuring product availability and fulfilling customer demand on-time. However, inefficient scheduling and vehicle routing from the distribution center may cause delivery delays and, thus, stock-outs on the store shelves. Therefore, optimization of vehicle routing can play a vital role in fulfilling customer demand. Methods: In this research, a case study is formulated for a chain of retail stores in Dhaka City, Bangladesh. Orders from various stores are combined, grouped, and scheduled for Region-1 and Region-2 of Dhaka City. The 'vehicle routing add-on' feature of Google Sheets is used for scheduling and navigation. An android application, Intelligent Route Optimizer, is developed using the shortest path first algorithm based on the Dijkstra algorithm. The vehicle navigation scheme is programmed to change the direction according to the shortest possible path in the google map generated by the intelligent routing optimizer. Results: With the application, the improvement of optimization results is evident from the reductions of traveled distance (8.1\% and $12.2 \%)$ and time $(20.2 \%$ and $15.0 \%)$ in Region-1 and Region-2, respectively. Conclusions: A smartphone-based application is developed to improve the distribution plan. It can be utilized for an intelligent vehicle routing system to respond to real-time traffic; hence, the overall replenishment process will be improved.
\end{abstract}

Keywords: route optimization; intelligent application; Android Studio 4.0; Google Sheet; Dhaka city map

\section{Introduction}

Nowadays, Industry 4.0 is transforming the physical, digital, and virtual systems through numerous connections with different entities [1]. Supply chain (SC) digitalization emanates from the communication and coordination [2] in a real-time situation to increase organizational competencies [3] by embracing digital tools [4]. Moreover, digitalization has caused significant economic shifts in supply chain management (SCM) as the demand for products and services is growing exponentially due to globalization. Thus, a great opportunity is arising for SCM to be the focal point of competitive advantage in business. The basic components of SC are organizations, consumers, operations, and information. The most significant aspects of SCM are categorized as procurement, production, and delivery [5]. Thus, management of transportation has become a vital issue for an organization to increase its operating performance, customer loyalty, and profitability [6].

The SCM system is driven by customer demands, the type of goods to be produced, raw materials to be used, manufacturing methods, delivery schedule, and transportation at the end. A key characteristic of SCM is its changing nature which emerges from the movement of inventory, cash, and information among the network entities [7]. The management of these flows falls under the purview of logistics functions for scheduling and routing activities [8]. The efficacy of the logistics system depends on the vehicle scheduling 
and routing optimization, which influences the profitability and customer satisfaction. The vehicle routing problem (VRP) deals with the issues that arise when the vehicles are scheduled and operated from the hub (initial location) to deliver products to customers (several locations) [9]. The solution of VRP is a group of optimal routes; those routes start and end in the hub, satisfying demands by serving customers. The process requires route selection, estimating alternate routes, and predicting driving time based on criteria variables, objective functions, and constraints [10].

Moreover, the revolutions in transportation systems, telecommunications, and vehicular technologies create opportunities for controlling the supply chain and logistics operations [11]. An intelligent transportation system develops the capability to guide the driver to the destination by providing optimal routing information in real-time traffic conditions [12] and/or by finding optimal routes with less fuel consumption [13]. Therefore, adopting innovative technologies for autonomous vehicles, big data, and the internet of things (IoT) will resolve unforeseeable challenges in the transportation sector [14]. Furthermore, cloud computing increases supply chain efficiency through increased visibility and collaboration in order processing, inventory management, warehousing, and logistics [15]. The assimilation of Internet of Things (IoT) to cloud-based system enables dynamic management of vehicle routing operations by inter-communication, connection, and action among various supply chain components [10] as proposed in Figure 1.

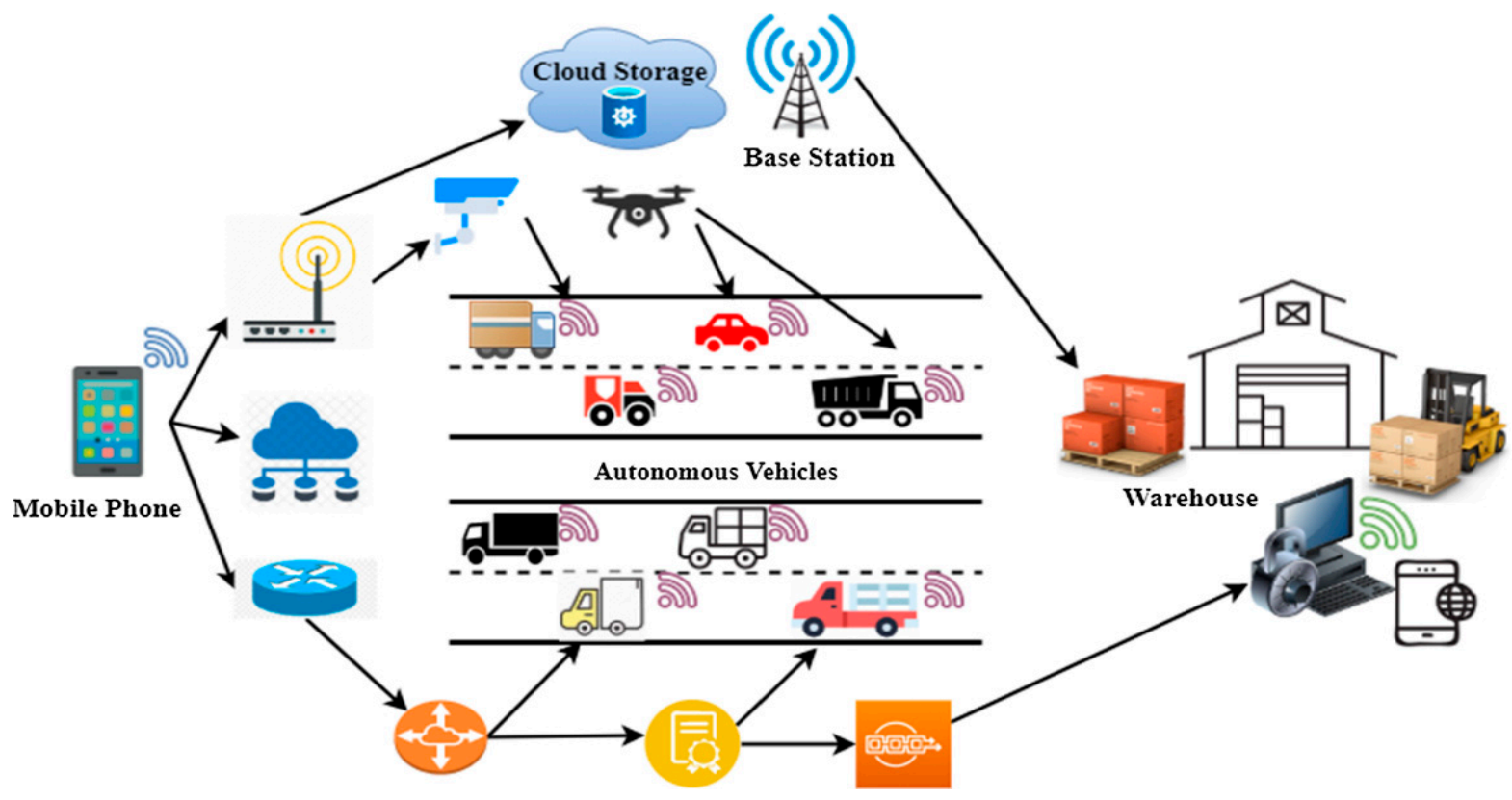

Figure 1. IoT-assisted intelligent logistics transportation management framework [10].

In the retail industry, artificial intelligence (AI) applications are increasing in various areas of ordering, processing, and transporting goods [16]. Autonomous transport systems are used in intralogistics for optimizing alternative routes [17]. Machine learning (ML) is used at Amazon for each shipment's ideal packaging size selection [18]. An intelligent AI application, called Eden, was launched by the global US retail group Walmart to optimize its supply chain by inspecting the freshness of fruit and vegetables [19]. The use of mobile applications has led innovations through various logistics process of e-grocery retail in South Africa [20].

In Bangladesh, chains of retail stores were started with the aim of providing qualitygoods at reasonable prices with a comfortable shopping experience [21]. The chain stores (also known as super shops) maintain customer satisfaction to achieve a competitive advantage in the retailing sector [22]. The key points identified for retail chain service improvement are pleasant shopping conditions, better services, a variety of goods, and 
efficient supply management [23]. The key challenge for a retail chain is to distribute all the products from the warehouse to the stores at the right time at the right place with ensured quality. Moreover, the distribution cost is on the higher side, which needs optimization for a profitable and sustainable retail business [24]. Hence, vehicle routing plays a crucial role for a super shop chain to supply products to its different outlets. In the absence of proper vehicle routing, the driver of a vehicle moves from one outlet to another randomly, and thereby increases both the traveling distance and time. An intelligent vehicle routing system can help to fulfill increased customer service expectations by responding to the real-time traffic condition for route optimization to reach the destination points. Therefore, in this paper, an attempt has been taken to make the vehicle routing of a chain of retail stores effective and automotive by making it intelligent.

\section{Literature Review}

\subsection{Vehicle Routing Problem}

Vehicle routing problem (VRP) focuses on determining the optimal vehicle route to fulfill customer demands with minimum distance (time or cost). This concept was introduced to find the optimal paths by minimizing the traveling distances of petrol delivery trucks [25]. Subsequently, many vehicle routine problems were formulated with various logistical applications. In particular, a time slot is maintained for delivery in the VRP with time windows to find appropriate solutions for several real-life problems in manufacturing, scheduling, and logistics. Pickup and delivery with time windows using limited vehicles are considered for delivering several transport requests [26]. The dynamic vehicle routing problem (DVRP) with time windows model was developed to reduce the vehicle cost using real-time travel information. The two components of flow simulation and route choice simulation is linked in the block density model [27], as shown in Figure $2 \mathrm{a}$, where the shortest path is chosen at a node. Real-time routing and dispatching problems were solved by implementing parallel strategies for route re-optimization and computation [28]. A model was developed to find an optimal route by simulating and updating the route plan regularly according to the real-time traffic in Smart Cities [29]. In this model, the classical Dijkstra algorithm [30] was used to find the shortest path in a city map. Emergency vehicle routing was simulated for earthquake conditions in Okayama City, Japan, by using a modified Dijkstra algorithm [31].

\subsection{Big Data, IoT and Intelligent Transportation}

Big-data based algorithms are increasingly used in intelligent transportation systems (ITS) for a variety of applications in recognition of traffic signals, detection of objects, prediction of traffic flow, and planning of travel times and routes [32]. One such example is the development of an Android application for automatic capturing and image processing using mobile devices' integrated camera systems for the detection of stolen cars, management of parking systems, and verification of license plates [33]. Very recently, nine disruptive technologies such as additive manufacturing, artificial intelligence (AI), automated robots, autonomous vehicles, big data analytics, blockchain, drones, electric vehicles (EV), and the internet of things (IoT) were identified as the emerging disruptive technologies expected to affect logistics and transportation [34]. Intelligent cloud-based technology is making a significant impact on the logistics sector, as cloud computing is used for autonomous logistics to synchronize the real time flow of material and information [35]. IoT utilizing cyber-physical systems (CPS), equipped with electronics and software, connects the physical system with the digital world to optimize the system's performance [36]. Vehicular cyber-physical systems (VCPS) are designed for smart roads by realizing mobile cloud computing services where vehicles and mobile devices are connected to both cloud servers and clients [37], as illustrated in Figure 2b. Open source VRP Spreadsheet Solver designed to work by storing information in the server console and supplying information to the worksheet of locations, distances, vehicles, solution and visualization [38], as shown in Figure $2 \mathrm{c}$ with the illustration of information flow. A smartphone-based prototype appli- 
cation was developed for cargo transportation using an information and communication technology (ICT) based service [39].
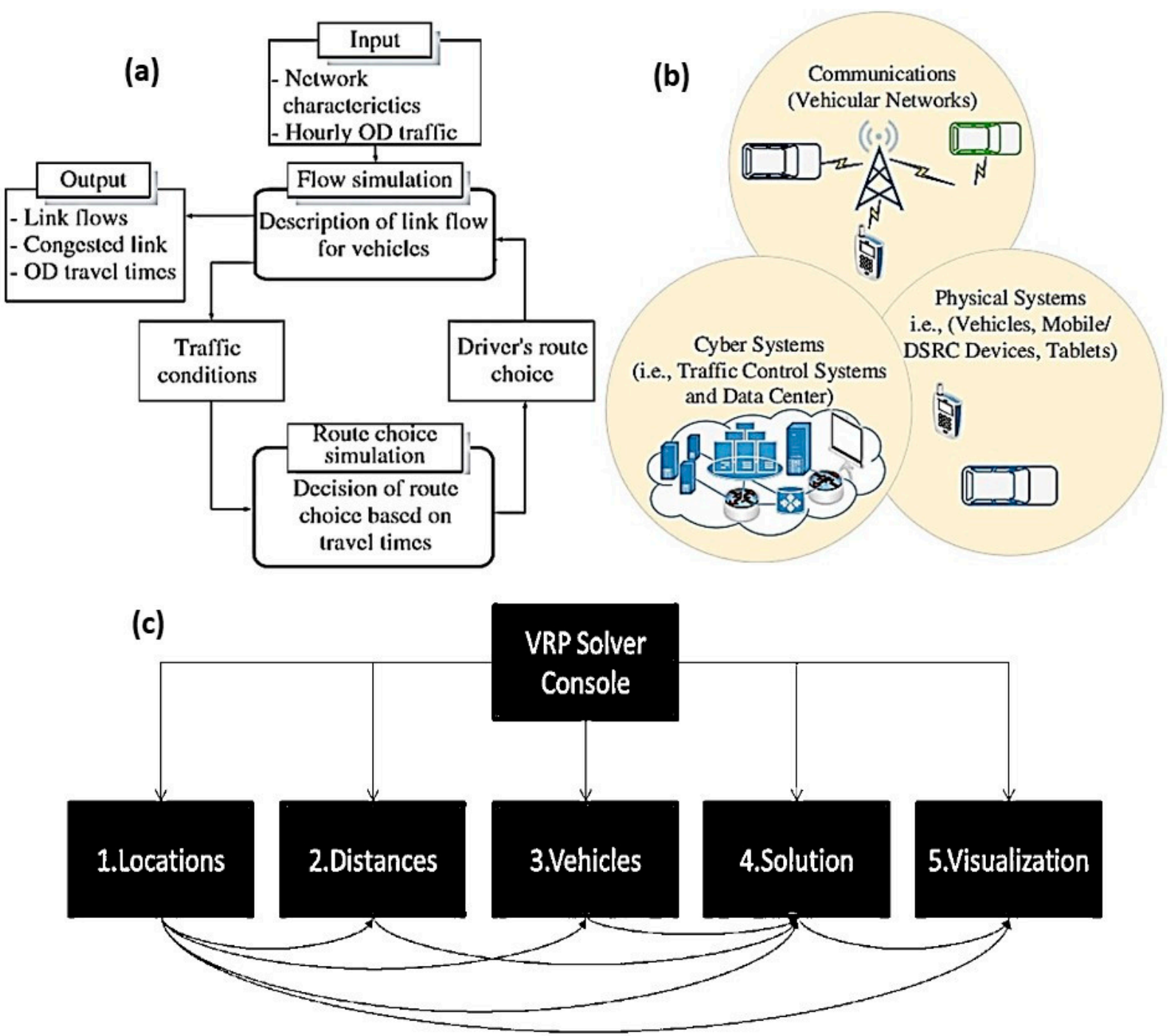

Figure 2. (a) Structure of the block density model [27] (b) Vehicular Cyber Physical System (VCPS) [37] (c) Spreadsheet structure of VRP Spreadsheet Solver [38].

\subsection{Pathfinding, Scheduling and Intelligent Navigation}

The pathfinding analysis, used for various sectors of logistics and transportation network operation, identifies the shortest path to solve the fundamental vehicle routing problem [40]. An algorithm was developed for the shortest pathfinding from the perspective of space and time complexity [41] in a sequence of partial graphs with original graph growth [42]. The shortest path analysis using artificial intelligence based on linear graph theory applied to avert obstacles on routes [43]. A mobile application was developed for agricultural product logistics by using Dijkstra's algorithms to calculate the shortest path to discover the transportation routes [44]. Ant Colony Optimization was recently adopted to solve multiple delivery routing problems for E-logistics service providers [45].

An online scheduling approach combined qualitative and quantitative research methods using operational research and artificial intelligence to solve the vehicle routing problem for B2C e-commerce urban logistic problems [46]. By incorporating the intelligent system of traffic image processing and shortest path first algorithm, the traveling time can be reduced significantly. The shortest available path was determined by knowing the real-time traffic conditions to effectively navigate the driving [47]. An Android application 
for a smartphone was developed for real-time decision-making involving traffic conditions on the road [48]. Using graph theory and shortest path algorithm, a mobile map was designed and developed to find the shortest and quickest route between two locations [49]. To make the vehicle routing algorithms practical, global positioning system (GPS) data was used for the algorithms to provide the optimal solution to a real-world scenario [50]. A system was developed to automatically gather information using sensors attached to the vehicle and transmit information through GSM-enabled devices. An intelligent monitoring system was developed by using GPS, Google Maps, and cloud computing to take all the necessary inputs of the vehicles like their real-time location, fuel level, driver conditions, and speed [51]. An online map service was used to develop a dynamic vehicle routing system to respond to real-time customer demands cost-effectively with improved visual effects [52]. An Android application was developed for the optimal tour (shortest distance) using the Genetic Algorithm and was implemented using the Google API [53]. The essential elements of the navigation system are the minimalist path algorithm and up-to-date road networks on the maps [54]. An AI based transportation system is crucial for the development of mechanical intelligence [55] for Smart Connected Logistics (SCL) systems, making it more complex, automated, intelligent, and adaptive [56].

From the above review of the literature, it is realized that dynamic vehicle routing and scheduling optimization can be an efficient way to attain the optimal output for better adaptability and performance. Hence, the current research aims to implement application-based intelligent vehicle routing for a chain of retail stores to respond in real-time traffic conditions.

\section{Problem Identification and Solution Approach}

Consider a chain of retail superstores facing challenges distributing several products from its warehouse to different outlets/stores due to scheduling and routing issues. The retail chain is located in Dhaka, Bangladesh, and experiences an inefficient distribution plan with higher transportation costs [24]. Thus, this research was carried out to optimize the scheduling and vehicle routing in supplying goods from the distribution center to outlets. As a current practice, manual scheduling and routing are used to deliver products using limited capacity vehicles. Hence, the optimal output is not achieved due to the extra traveling of vehicles. Moreover, the traffic conditions in Dhaka city are often affected by congestion and traffic jams. Therefore, an optimal route is required to respond to the dynamic traffic conditions. Additionally, navigating on the road without knowing the real-time traffic conditions undermines the product delivery target for the stores. Hence, this paper attempts to implement intelligent vehicle routing and scheduling to improve the distribution system by reducing the transportation distance and time. Daily demand information obtained for two different commodities (rice and pulse) for 87 stores/outlets is shown graphically in Figure 3. Demands are fulfilled daily from the central warehouse (depot) using the vehicles (covered van) to the store/outlets.

The capital city of Bangladesh, also known as of Dhaka City Corporations (North and South), lies between $23.69^{\circ}$ and $23.89^{\circ}$ North latitudes and $90.33^{\circ}$ and $90.44^{\circ}$ East longitudes [57]. Due to inadequate space and road infrastructure, frequent traffic congestion results in severe economic losses in the transport system in Dhaka city [58]. The government has initiated comprehensive transport planning and infrastructure programs to improve the traffic conditions [59]. This initiative has increased wider roads and improved the traffic conditions in the newly developing areas (North-East part) of Dhaka city. Thus, a dotted line has been drawn on the map of Dhaka city [60] to identify newly developing areas (Region-1) and old areas (Region-2), as shown in Figure 4. In this study, transportation assignments were considered for vehicle routing as vehicle V1 and V2 for Region-1 and V3 and V4 for Region-2, respectively.

This study collected data through a physical questionnaire survey with four delivery vehicles' drivers and the operation head. The demand at the outlet is known the day before delivery. The total minimum demand for rice and pulses is $500 \mathrm{~kg}$, while the total 
maximum demand is $2000 \mathrm{~kg}$. Four vehicles with limited capacities were assigned for scheduling and routing purposes. Vehicles 1 and 2 were considered for Region-1, while vehicles 3 and 4 were considered for Region-2. The maximum capacity of the vehicle (total weight of rice and pulse) is $6000 \mathrm{~kg}$. It was assumed that each vehicle visits one node (store/outlet) only once. The first node was considered as a depot (warehouse). Each vehicle starts its journey from the depot, delivers the goods at nodes (stores), and ends the journey at the depot. The daily demand at nodes does not exceed the capacity of the vehicle. From the 87 stores/outlets, sample data set with 10 outlets in Region-1 and Region-2 were selected with location information such as latitude, longitude, addresses, postal code, and daily demand information, as listed in Tables 1 and 2.

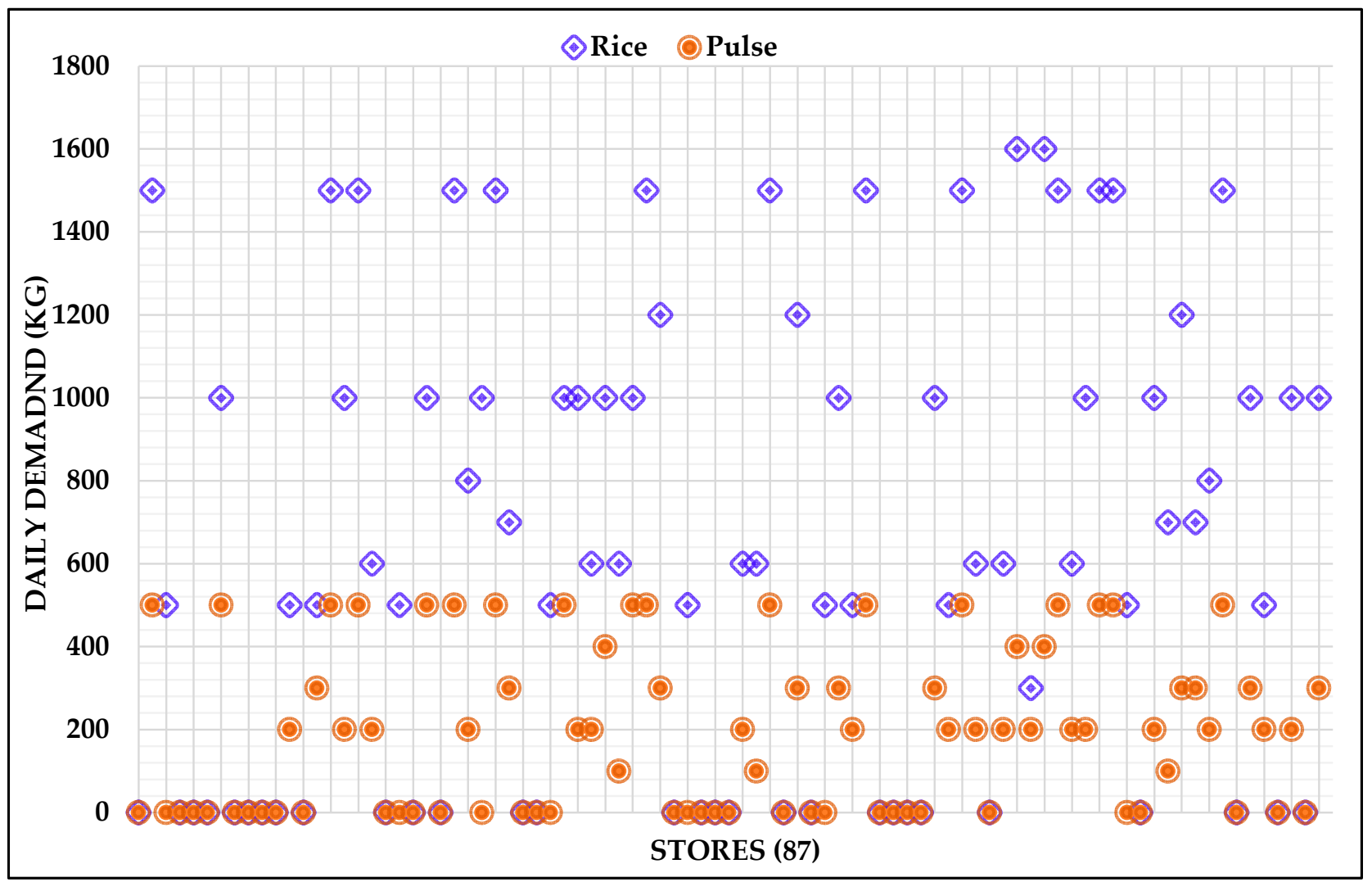

Figure 3. Daily demand of 87 stores for two different commodities of rice and pulse.

Table 1. Depot (Warehouse) and Delivery Locations (Outlet) information in Region-1 for assignment of vehicles 1 and 2.

\begin{tabular}{|c|c|c|c|c|c|c|c|c|}
\hline \multirow{2}{*}{ Store ID } & \multirow{2}{*}{ Latitude } & \multirow{2}{*}{ Longitude } & Address & \multirow{2}{*}{ Postal Code } & \multirow{2}{*}{ ORDER ID } & \multirow{2}{*}{ Rice (kg) } & \multirow{2}{*}{ Pulse (kg) } & \multirow{2}{*}{ Total (kg) } \\
\hline & & & (Region-1) & & & & & \\
\hline Depot (D) & 23.7679 & 90.4039 & \multirow{2}{*}{$\begin{array}{c}\text { Novo Tower, 270, Tejgaon Industrial Area } \\
\text { Plot-32/D\&E, Nator Tower, RD-02, Sector-03, } \\
\text { Uttara }\end{array}$} & 1208 & & & & \\
\hline Outlet 1 & 23.8639 & 90.3971 & & 1230 & Order 1 & 1500 & 500 & 2000 \\
\hline Outlet 2 & 23.814 & 90.3237 & \multirow{3}{*}{$\begin{array}{c}\text { Plot \# 27, Road \# 02, Sector \# 11, Uttara. } \\
\text { House-12, Road-12, Sector-10, Uttara } \\
\text { 1-18, Kawla Bazar, Civil Avn Mkt, } \\
\text { Dakshinkhan }\end{array}$} & 1230 & Order 2 & 500 & 0 & 500 \\
\hline Outlet 3 & 23.8818 & 90.3886 & & 1230 & Order 3 & 1000 & 500 & 1500 \\
\hline Outlet 4 & 23.8458 & 90.4179 & & 1229 & Order 4 & 500 & 200 & 700 \\
\hline Outlet 5 & 23.834 & 90.4154 & \multirow{2}{*}{$\begin{array}{c}\text { House-1/C, 1/D, Road-16, Nikunja-2, Khilkhet } \\
\text { House- } 14 \text { \& 30-B, Blk-B, North Banasree, } \\
\text { Rampura }\end{array}$} & 1229 & Order 5 & 500 & 300 & 800 \\
\hline Outlet 6 & 23.7647 & 90.4291 & & 1219 & Order 6 & 1500 & 500 & 2000 \\
\hline Outlet 7 & 23.7646 & 90.4291 & \multirow{3}{*}{$\begin{array}{c}\text { Block-K, South Banasree, Rampura } \\
\text { 3/2, Sky view Plaza, Mugdapara, Sabujbagh } \\
\text { House-12, H Avenue Rd No-08, Rampura, } \\
\text { Banasree }\end{array}$} & 1219 & Order 7 & 1000 & 200 & 1200 \\
\hline Outlet 8 & 23.729 & 90.4295 & & 1219 & Order 8 & 1500 & 500 & 2000 \\
\hline Outlet 9 & 23.7612 & 90.4293 & & 1219 & Order 9 & 600 & 200 & 800 \\
\hline \multirow[t]{2}{*}{ Outlet 10} & 23.8098 & 90.3865 & Shop-05, Plot-60, RD-07, Banasree, Rampura & 1219 & Order 10 & 500 & 0 & 500 \\
\hline & & & & \multicolumn{2}{|c|}{ Total } & 9100 & 2900 & 12,000 \\
\hline
\end{tabular}


Table 2. Depot (Warehouse) and Delivery Locations (Outlet) information in Region-2 for assignment of vehicle 3 and 4.

\begin{tabular}{|c|c|c|c|c|c|c|c|c|}
\hline \multirow{2}{*}{ Store ID } & \multirow{2}{*}{ Latitude } & \multirow{2}{*}{ Longitude } & Address & \multirow{2}{*}{ Postal Code } & \multirow{2}{*}{ ORDER ID } & \multirow{2}{*}{ Rice (kg) } & \multirow{2}{*}{ Pulse (kg) } & \multirow{2}{*}{ Total (kg) } \\
\hline & & & (Region-2) & & & & & \\
\hline Depot (D) & 23.7679 & 90.4039 & Novo Tower, 270, Tejgaon Industrial Area & 1208 & & & & \\
\hline Outlet 11 & 23.7986 & 90.3706 & 544/2-C, Kazipara, Mirpur & 1216 & Order 1 & 800 & 200 & 1000 \\
\hline Outlet 12 & 23.7986 & 90.3654 & 558 East Kazipara, Mirpur & 1216 & Order 2 & 700 & 300 & 1000 \\
\hline Outlet 13 & 23.7963 & 90.3513 & 3/A, City Centre, Darussalam RD, Mirpur-01 & 1216 & Order 3 & 1000 & 500 & 1500 \\
\hline Outlet 14 & 23.7986 & 90.3654 & 1/2 Arsin Gate, Eastern Housing Society & 1216 & Order 4 & 600 & 100 & 700 \\
\hline Outlet 15 & 23.7743 & 90.3578 & Plot-01, Dhaka Housing Ring Road, Shamoli & 1207 & Order 5 & 300 & 200 & 500 \\
\hline Outlet 16 & 23.7683 & 90.3481 & $\begin{array}{c}\text { 29, Kaderabad Housing, Katasur, } \\
\text { Mohammadpur }\end{array}$ & 1207 & Order 6 & 1600 & 400 & 2000 \\
\hline Outlet 17 & 23.7621 & 90.3559 & 04, Mohammadi Housing Ltd., Mohammadpur & 1207 & Order 7 & 1500 & 500 & 2000 \\
\hline Outlet 18 & 23.7621 & 90.3493 & $\begin{array}{c}\text { 20/11, Tajmohal Road, Block C, } \\
\text { Mohammadpur }\end{array}$ & 1207 & Order 8 & 1000 & 200 & 1200 \\
\hline Outlet 19 & 23.7527 & 90.3724 & $\begin{array}{l}\text { 55-2, Qazi Nuruzzaman Sarak, West } \\
\text { Panthapath }\end{array}$ & 1205 & Order 9 & 700 & 100 & 800 \\
\hline \multirow[t]{2}{*}{ Outlet 20} & 23.7396 & 90.3631 & 68/C, Jigatala, Dhanmondi, Dhaka-1209. & 1209 & Order 10 & 600 & 200 & 800 \\
\hline & & & & \multicolumn{2}{|c|}{ Total } & 8800 & 2700 & 11,500 \\
\hline
\end{tabular}

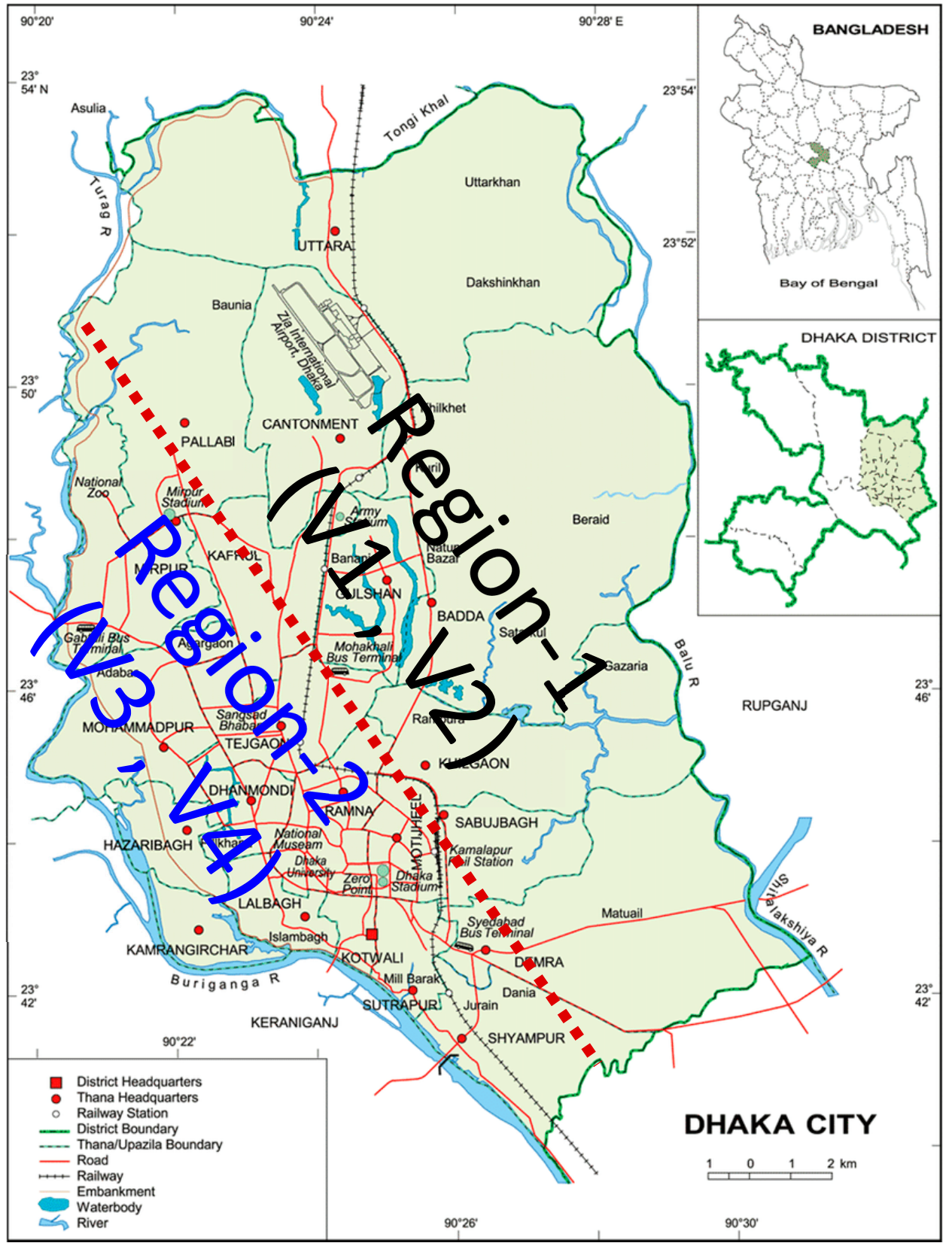

Figure 4. Vehicle coverage area allocation for Region-1 and Region-2 as shown in the map of Dhaka city. 


\section{Intelligent Vehicle Scheduling and Routing}

Intelligent vehicle routing is demonstrated by finding the shortest path between nodes (outlets) through a two-step procedure of scheduling and routing utilized to identify the optimal vehicle routing for a chain of retail stores/outlets. The methodology was developed by using the demands of different outlets, combining those demands, and clustering these by territory/region. The scheduling and routing plans were developed by considering the vehicle capacity (weight) constraints.

\subsection{Scheduling Process}

The scheduling process considers the maximum number of stores/outlets that a vehicle can attend with its capacity-constraint (weight) based on the demand at nodes (outlets). The approach appoints the minimum number of vehicles required to serve the nodes (outlets), thereby reducing the number of vehicles. An open-source spreadsheet-based solver can be used for the Vehicle Routing Problem (VRP) where the server console stores information for other worksheets (elements) of locations, distances, vehicles, solutions, and visualizations [38], as is illustrated in Figure 2c. Google Sheets, a free web-based spreadsheet application, was used for vehicle scheduling in the present study. To integrate the road traffic condition, the vehicle routing add-on feature is added on the Google Sheet. Figure 5 shows the key features of the vehicle routing add-on and options for the route solver worksheet developed by Zagetoo [61]. Therefore, manual human efforts were needed less for scheduling the activity due to using the added feature of location and route visibility on Google Maps. The application solver uses information about the store's demand, location, available vehicle, and vehicle capacity constraints for scheduling and routing solutions in real-time traffic conditions.

(a)

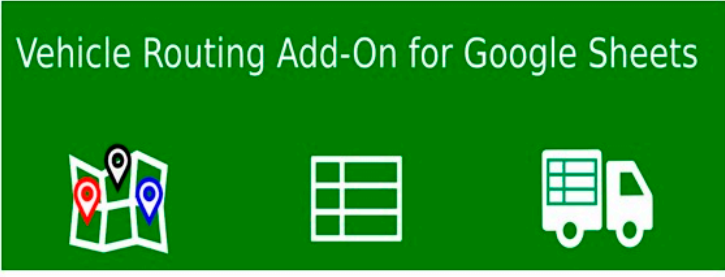

\section{Zagetdoo}

Main Features of Vehicle Routing Add-On

$\checkmark$ Suitable for planning daily vehicle routes

$\checkmark$ Find best routes based on fixed and variable costs

$\checkmark$ Reduce time and effort of human planners

$\checkmark$ Apply routing (distances and travelling times) based on traffic

$\checkmark$ Handle multiple depots with up to one thousand orders

$\checkmark$ Consider capacity constraints and time windows

$\checkmark$ Import latitudes, longitudes from KML files or geocoding

$\checkmark$ View locations and vehicle routes on a Map

\section{Why Google Sheets?}

$\checkmark$ Free and easy web-based spreadsheet application

$\checkmark$ Secure authentication via Google user accounts

$\checkmark$ Add-on reads and sends request to solver server

(b) ExampleDelivery

ت Fille Edit View Insert Format Data Tools Add-ons Help All changes saved in Drive

\begin{tabular}{|c|c|c|c|c|c|c|c|c|c|c|c|}
\hline \multicolumn{2}{|c|}{$n \rtimes \bar{\nabla}$} & $100 \% \cdot$ & \& $\% .0$ & .00123. & \multicolumn{2}{|c|}{ Document add-ons } & B $I \sim A$ & ‥ $⿴ 囗 十 2$ & \multicolumn{2}{|c|}{$\equiv \cdot \frac{ \pm}{\dagger} \cdot|p| \cdot \nabla \cdot$} & $\wedge$ \\
\hline \multirow[t]{2}{*}{$f x$} & \multicolumn{4}{|l|}{ Vehicle ID } & \multirow{2}{*}{\multicolumn{2}{|c|}{ Vehicle Routing }} & \multirow{2}{*}{\multicolumn{2}{|c|}{ Load examples }} & & & \\
\hline & A & $B$ & C & & & & & & G & H & \\
\hline 1 & \begin{tabular}{|l|} 
Vehicle ID \\
\end{tabular} & Stop & Order ID & Loca & \multicolumn{2}{|c|}{ Get add-ons... } & \multirow{2}{*}{ Get LatlLong from } & & garture Time (Plan) & & \\
\hline 2 & Vehicle 1 & 0 & 0 & Depot & \multirow{2}{*}{\multicolumn{2}{|c|}{ Manage add-ons... }} & \multirow{3}{*}{\multicolumn{2}{|c|}{ View all locations }} & 09:56 & & \\
\hline 3 & Vehicle 1 & 1 & Order 3 & Wat Pho & & & & & $10: 01$ & & \\
\hline 4 & Vehicle 1 & 2 & Order 2 & \multicolumn{3}{|c|}{ Wat Phra Kaew } & & & $10: 05$ & & \\
\hline 5 & Vehicle 1 & 3 & Order 5 & \multirow{2}{*}{\multicolumn{2}{|c|}{$\begin{array}{l}\text { Wat Rakangkositaram } \\
\text { Wat Arun }\end{array}$}} & Visit & \multirow{2}{*}{\multicolumn{2}{|c|}{ Solve vehicle routes }} & $10: 18$ & & \\
\hline 6 & Vehicle 1 & 4 & Order 1 & & & Visit & & & $10: 24$ & & \\
\hline 7 & Vehicle 1 & 5 & Order 4 & \multirow{2}{*}{\multicolumn{2}{|c|}{ Wat Kalayanamit }} & Visit & \multicolumn{2}{|l|}{ Get vehicle routes } & $10: 29$ & & \\
\hline 8 & Vehicle 1 & 0 & 0 & & & End & \multirow{2}{*}{\multicolumn{2}{|c|}{ View vehicle roules }} & $10: 35$ & & \\
\hline 9 & Vehicle 2 & 0 & 0 & \multicolumn{2}{|l|}{ Depot } & Start & & & $09: 53$ & & \\
\hline 10 & Vehicle 2 & 1 & Order 6 & Wat Suthat & & Visit & \multirow{2}{*}{\multicolumn{2}{|c|}{ Check your quota }} & $10: 01$ & & \\
\hline 11 & Vehicle 2 & 2 & Order 8 & \multicolumn{2}{|l|}{ Wat Saket } & Visit & & & $10: 05$ & & \\
\hline 12 & Vehicle 2 & 3 & Order 9 & \multirow{3}{*}{\multicolumn{2}{|c|}{$\begin{array}{l}\text { Wat Bowonniwet Vihara } \\
\text { Wat Chanasongkhram } \\
\text { Depot }\end{array}$}} & Visit & \multirow{2}{*}{\multicolumn{2}{|c|}{ Settings }} & $10: 12$ & & \\
\hline 13 & Vehicle 2 & 4 & Order 7 & & & Visit & & & $10: 16$ & & \\
\hline 14 & Vehicle 2 & 0 & 0 & & & End & & $0: 30$ & $10: 30$ & & \\
\hline
\end{tabular}

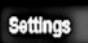

User ID

Access key

Access key

Google Maps API key

Map languages

English

Routing types

Shortest with Traffic $\rightarrow$ Car

Figure 5. (a) Vehicle Routing Add-On features (b) delivery worksheet options in the vehicle routing solver. 
To begin the scheduling process, a Google spreadsheet was opened from the desktop browser and 'vehicle routing add-on' was added to the Google Sheet. Information from Table 1 was added in the location tab for the location ID, latitude, longitude, address of depot (warehouse), and outlets (stores). Then, vehicle and order information was added to the vehicle and order sections accordingly by following the procedure of Zagetoo [61]. The application solves the problem once "Solve Vehicle Routes" is clicked. Visualization is seen from "View vehicle routes" feature. Moreover, the route sequencing of vehicles is available at "Route" section at the footer. Once all the necessary information was updated for vehicle 1 and vehicle 2 in Region-1, the vehicle routing solver worked to maximize capacity utilization and cover the maximum number of outlets (stores). The solution of scheduling and delivery sequence for Region-1 is shown in Figure 6.

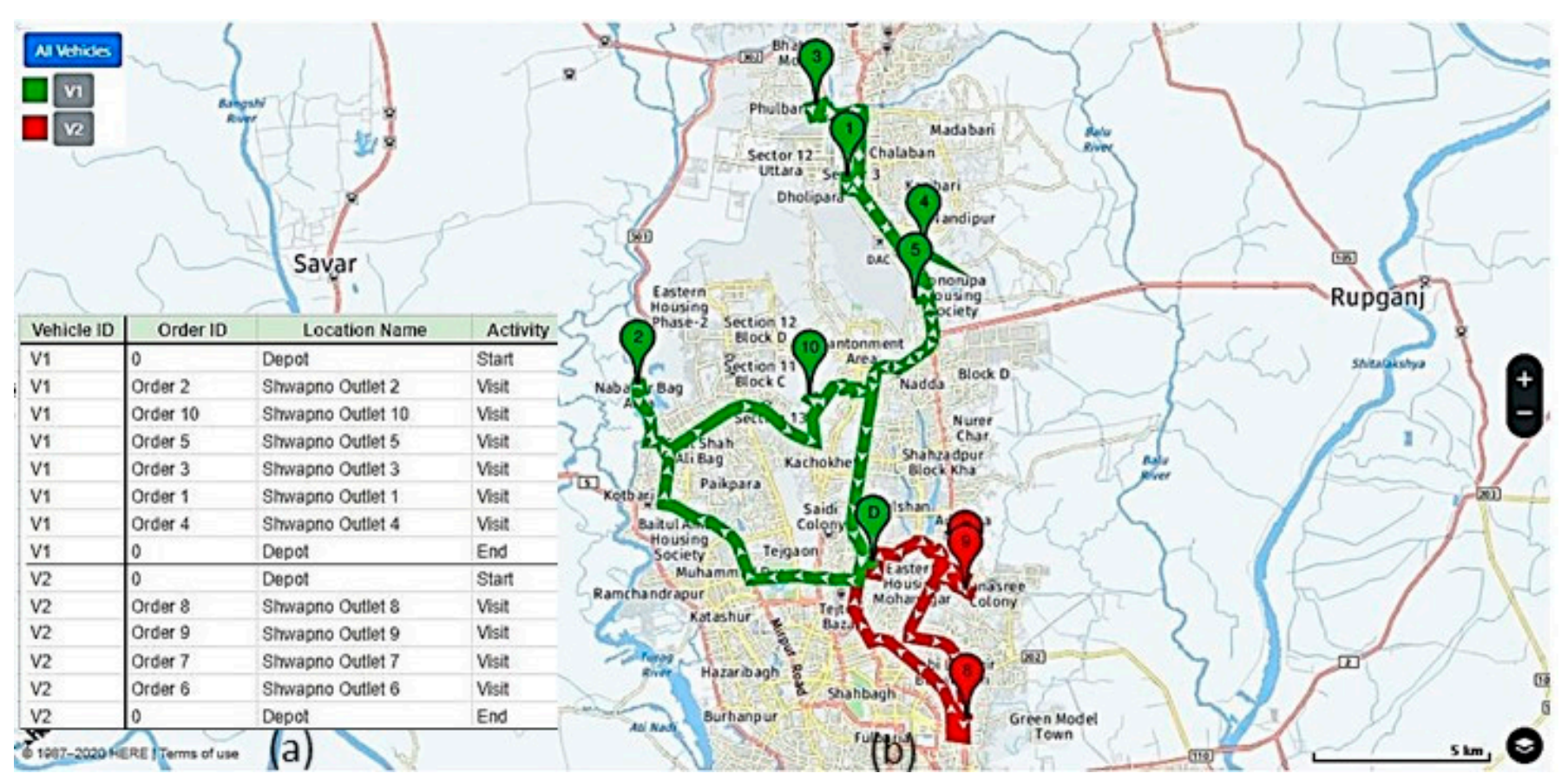

Figure 6. (a) Scheduling (b) Navigation sequencing of vehicle 1 and 2 for Region-1.

For scheduling of vehicle 3 and vehicle 4 in Region-2, the latitude and longitude of outlet location information listed in Table 2 was added. Then, the vehicle capacity (weight) and the order information were filled in according to the procedure mentioned earlier. Finally, the solution of delivery schedule was obtained for outlets 11 to 20 in Region-2, as shown in Figure 7. For vehicle-3, the order delivery sequence followed as "depot (start)-order 6-order 8-order 7-order 10-depot (return)". For vehicle 4, the order delivery scheduling plan started from the depot, delivered six orders, and returned to the depot.

\subsection{Development of Intelligent Route Optimizer Application (App)}

There are many ways to travel from one outlet to another, and thus, many nodes may arise from the depot to reach the destination (outlets). Moreover, as the road traffic conditions are constantly changing, navigating the vehicles based on instant traffic conditions from one outlet to another is crucial to obtain an efficient and optimal routing output. Therefore, the Dynamic Vehicle Routing Problem (DVRP) considers the optimization algorithm to monitor the movement of individual vehicles according to the traffic conditions [62]. In response to changes in the real-time traffic conditions, the optimizer can update the vehicles' schedules by re-optimizing the route. Therefore, in this study, an attempt was made to develop an intelligent route optimizer process flow shown in Figure 8 based on the vehicle routing approach [63] with the concept of real-time fleet management systems [64]. For the shortest traveling distance between the depot (warehouse) and nodes 
(outlets/stores), an appropriate weight was considered for the distance between them. The computation was progressed by choosing the smallest distance among the adjacent nodes' distances. The process continued for generating the path by identifying all adjacent nodes related to the current nodes. The nodes' weights were added to the current nodes to compute their distance to other nodes to reach the destination. However, the change of the nodes occurred only if it was less than the previous one. The weightage was calculated from previous nodes to current nodes based on adjacent nodes. After completing the algorithm, the shortest route was selected. If any obstruction arises on the selected path, the edges of weight re-evaluate and find another shortest path. Thus, the application (app) process flow was developed based on artificial intelligence to respond to the real-time data of traffic that makes the vehicle routing intelligent.

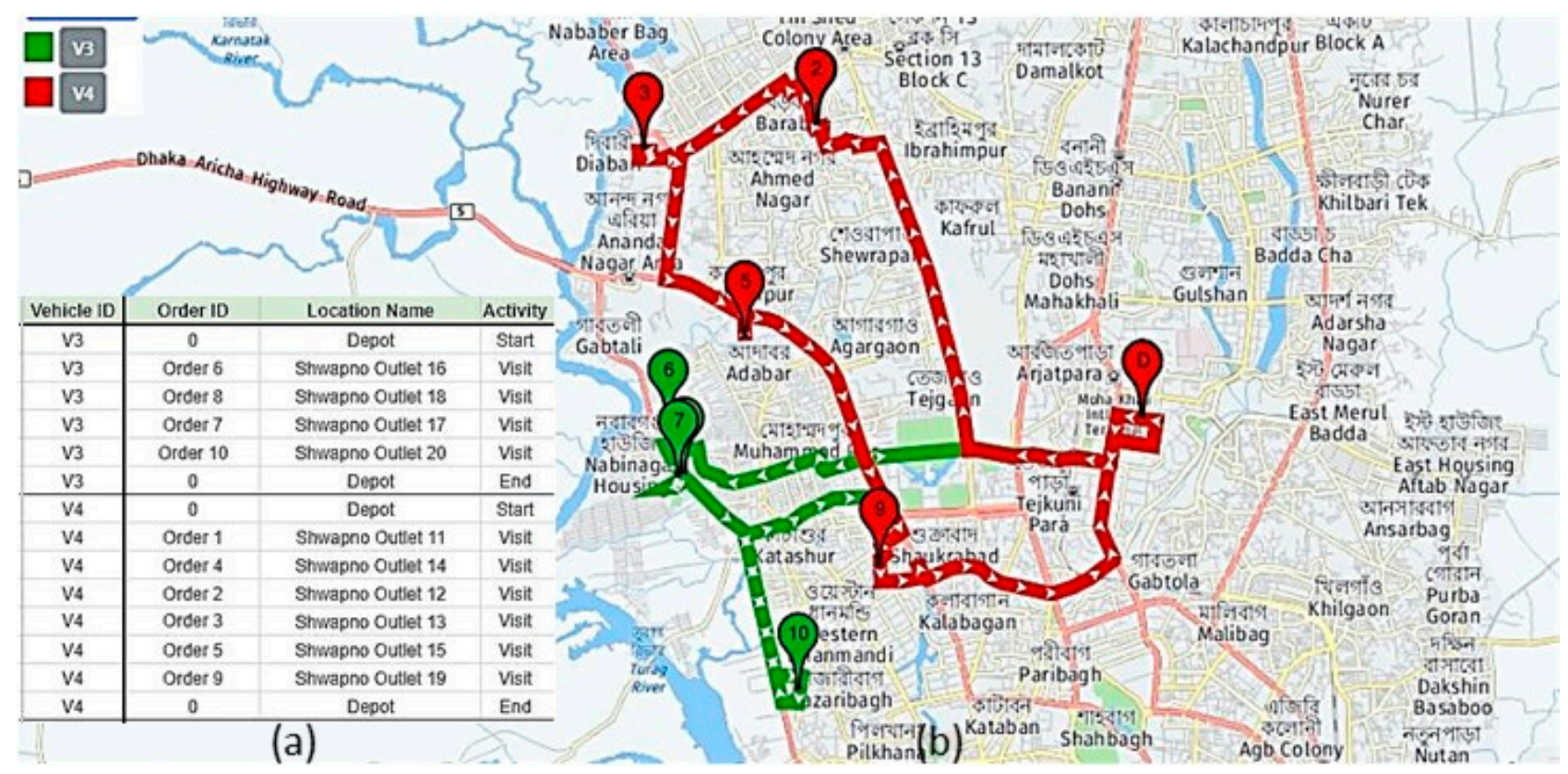

Figure 7. (a) Scheduling (b) Navigation sequencing of vehicles 3 and 4 in Region-2.

Internet and mobile applications significantly influence the transportation system, as travelers use traffic and navigation applications to aid their journey [65]. This is evident from the aspects of Industry 4.0 for enabling human-machine interaction (HMI) throughout a highly networked environment [66] of business management, production process and logistics [67]. Moreover, with the progress of digitalization through connectivity, the use of mobile applications (apps) increases due to the widespread diffusion of smartphones and devices [68]. Additionally, these devices can run standalone applications (apps) to access information via a web gateway, thus generating increased interest for mobile apps development among the independent developers [69]. The rapid adoption of Google's freely licensed operating system (OS) and the availability of the Android OpenSource Project (AOSP) accelerated the mobile apps development culture [70]. Android is a Linux-based open-source OS, where mobile apps are mostly developed using the Java programming language [71]. Consequently, the Android operating system (OS) has been widely accepted by software developers and non-expert users [72]. Android Studio offers an integrated development interface for developing the Android operating system [73], promoting Gradle base build support, quick troubleshooting, fast performance, and user usability and compatibility.

For this study, we developed an intelligent route optimizer app in the Google platform by utilizing the amiable operating system of Android Studio 4.0. The application icon is shown in Figure 9a. The map of Bangladesh is located on the user interface once the 
application icon is tapped, as shown in Figure 9b. The center location icon helps to identify the user's current location, as shown in Figure 9c.

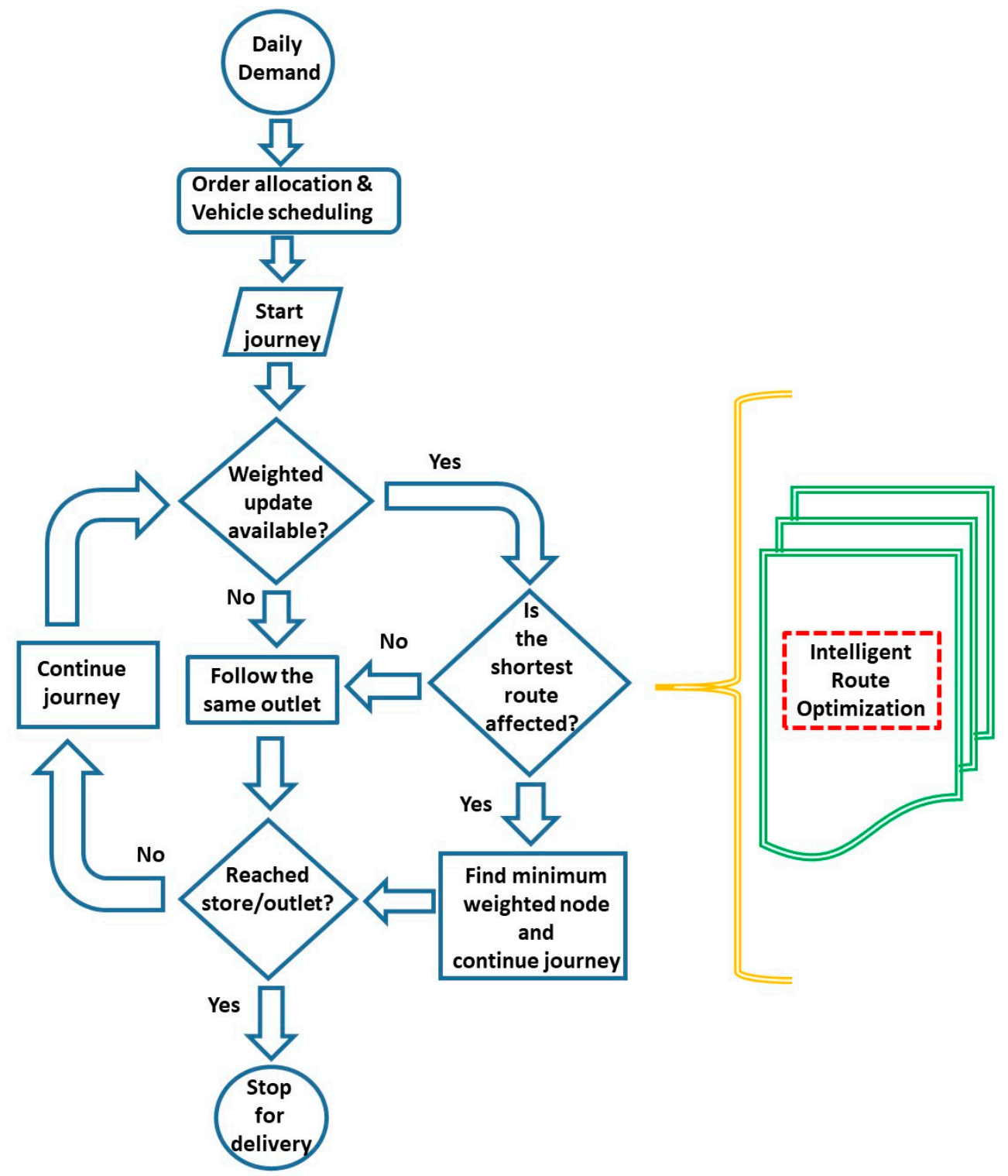

Figure 8. Intelligent vehicle routing optimization process flow.

The app was specifically designed for a chain of retail superstores to improve their transportation service. Java language was used to develop the application using the Android SDK (Software Development Kit) tool. The key feature of this application is to show the shortest path between the origin and destination points by generating the shortest routes with an alternative best route between the outlets. On the map, the 'Tap' feature was used in this app to select a destination point. The application was developed by using the Dijkstra algorithm, alternative path algorithm, and Google API key features. Dijkstra's shortest path algorithm is employed for road networks to determine the distance between origin and destination nodes. Edsger W. Dijkstra formulated the algorithm in 1956, and then after three years, it was published [74]. To reach the destination from the current location, many nodes may appear. The concept of the algorithm was used to continuously compute the shortest distance by eliminating the longer distances [75] during the optimization process. To plot the route between the nodes, the shortest path was retrieved and stored into a variable. Various tools from the Google cloud platform, 
such as real-time navigation and 'On Map Tap' features, were incorporated into the system for automatic decision-making.

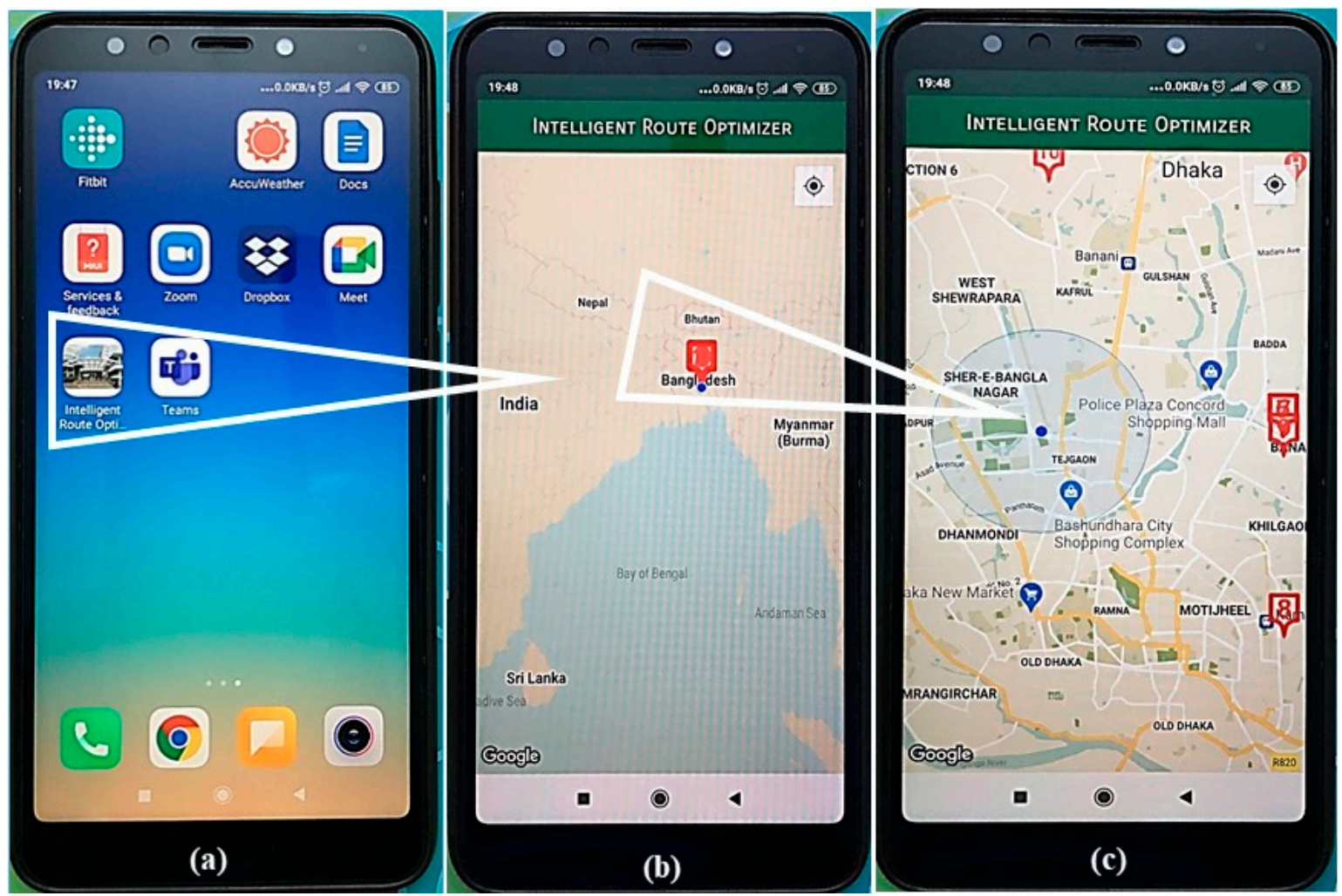

Figure 9. Overview of intelligent route optimizer showing (a) icon of the application (b) user application interface (c) current user location on the Google map.

\subsection{Application Interface}

The application was designed to incorporate intelligence in vehicle routing for a chain of retail stores to improve the transportation service. The application can generate the shortest routes with an alternative best route. Figure 10a illustrates the operation flowchart of the Intelligent Route Optimizer. The 'On Map Tap' feature was used so the user can tap the map to select a destination point. The application displays the shortest route with an alternative best route to the destination. This is the unique feature of the application, which generates the path once the location is tapped, compared to other VRP applications where the destination and location have to be selected manually.

Once the location sign is tapped, the app takes the current (instant) location. The stores/outlets are marked in their respective places. If any store location is tapped, the app immediately shows ways to reach that position with optimum and alternate methods. Figure 10b shows the illustration of the application where the vehicle starts a journey from the depot to visit five outlets from its initial depot point. The optimum routes are shown in a green color, and alternate routes are shown in an ash color in the Google map. Moreover, both the estimated distance and time of the proposed routing are shown once the blue marker is tapped. For example, the optimum routing will need an $18 \mathrm{~km}$ distance with an estimate of $57 \mathrm{~min}$, whereas alternate routing will require traveling a $19.82 \mathrm{~km}$ distance in $1 \mathrm{~h} 5 \mathrm{~min}$ time to reach outlet two, as illustrated in Figure 10c. 

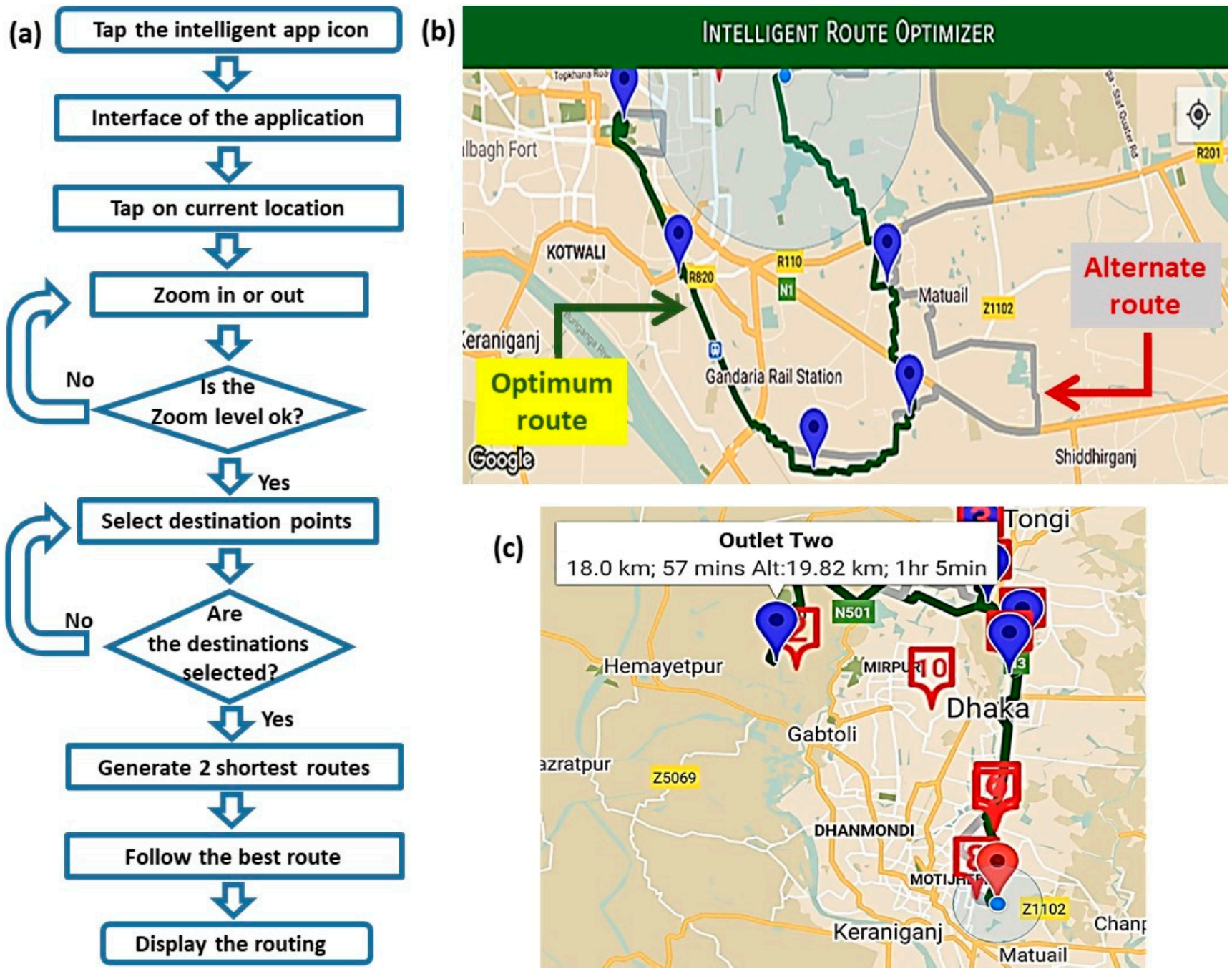

Figure 10. Illustration of (a) operation flowchart of intelligent route optimizer (b) journey routing showing optimum and alternate route option on Google Map (c) information showing distance and time of optimum and alternate routing to reach outlet two.

\subsection{Implementation Results}

The developed application was utilized for the delivery journey of vehicles in Region-1 and Region-2 according to the schedule and navigation scheme shown in Figures 6 and 7 in Section 4.1. In these journeys, the total traveling distance and time were investigated with and without using the application. While computing the traveling distance for individual vehicles, the depot (warehouse) distance to the first delivery outlet/store was recorded. Subsequently, the distance from the first delivery outlet/store to the second delivery outlet/store was recorded. This process was repeated until the vehicle returns to the depot. Similarly, the traveling time was recorded. The results of vehicle 1 and vehicle 2 are shown in Tables 3 and 4, respectively.

Comparison of the traveled distance and time before (without implementing the application) and after (upon implementing the application) is shown in Tables 3 and 4 for vehicle 1 and vehicle 2, respectively. During the travel, the distance became shorter or the same to reach the next node. The reduction of time was observed while traveling before (without the application) and after (with the application).

Similarly, the traveled distance and time before and after application used is shown for vehicle 3 and vehicle 4 in Tables 5 and 6, respectively. A reduced distance was observed during the travel, as the vehicle took a shorter way to reach the next node. The traveled time either shortened or remained the same to reach the next node. 
Table 3. Traveling distance before and after using the Intelligent Route Optimizer application for vehicle 1.

\begin{tabular}{|c|c|c|c|c|c|c|}
\hline Location Name & $\begin{array}{c}\text { Distance } \\
\text { (Before) (km) }\end{array}$ & $\begin{array}{c}\text { Distance } \\
\text { (After) }(\mathbf{k m})\end{array}$ & $\begin{array}{l}\text { Reduction in } \\
\text { Distance (km) }\end{array}$ & $\begin{array}{l}\text { Time (Before) } \\
\text { (min) }\end{array}$ & $\begin{array}{c}\text { Time (After) } \\
\text { (min) }\end{array}$ & $\begin{array}{l}\text { Reduction in } \\
\text { Time (min) }\end{array}$ \\
\hline Depot & 0.0 & 0.0 & 0.0 & 0.0 & 0.0 & 0.0 \\
\hline Outlet 2 & 10.0 & 9.2 & 0.8 & 53.0 & 40.0 & 13.0 \\
\hline Outlet 10 & 8.7 & 8.1 & 0.6 & 43.0 & 34.0 & 9.0 \\
\hline Outlet 5 & 7.0 & 7.0 & 0.0 & 27.0 & 23.0 & 4.0 \\
\hline Outlet 3 & 6.2 & 6.0 & 0.2 & 24.0 & 22.0 & 2.0 \\
\hline Outlet 1 & 3.3 & 3.1 & 0.2 & 12.0 & 10.0 & 2.0 \\
\hline Outlet 4 & 3.0 & 2.5 & 0.5 & 11.0 & 9.0 & 2.0 \\
\hline Depot & 7.5 & 6.2 & 1.3 & 25.0 & 22.0 & 3.0 \\
\hline
\end{tabular}

Table 4. Traveling distance before and after using the Intelligent Route Optimizer application for vehicle 2.

\begin{tabular}{ccccccc}
\hline Location Name & $\begin{array}{c}\text { Distance } \\
(\text { Before) } \mathbf{( k m )}\end{array}$ & $\begin{array}{c}\text { Distance } \\
(\mathbf{A f t e r}) \mathbf{( k m )}\end{array}$ & $\begin{array}{c}\text { Reduction in } \\
\text { Distance } \mathbf{( k m )}\end{array}$ & $\begin{array}{c}\text { Time (Before) } \\
(\mathbf{m i n})\end{array}$ & $\begin{array}{c}\text { Time (After) } \\
(\mathbf{m i n})\end{array}$ & $\begin{array}{c}\text { Reduction in } \\
\text { Time } \mathbf{( m i n )}\end{array}$ \\
\hline Depot & 0.0 & 0.0 & 0.0 & 0.0 & 0.0 & 0.0 \\
Outlet 8 & 8.1 & 7.4 & 0.7 & 49.0 & 38.0 & 11.0 \\
Outlet 9 & 5.5 & 5.1 & 0.4 & 41.0 & 32.0 & 9.0 \\
Outlet 7 & 3.0 & 2.5 & 0.5 & 20.0 & 14.0 & 6.0 \\
Outlet 6 & 2.8 & 2.3 & 0.5 & 17.0 & 14.0 & 3.0 \\
Depot & 5.0 & 5.0 & 0.0 & 25.0 & 19.0 & 6.0 \\
\hline
\end{tabular}

Table 5. Traveling distance before and after using the Intelligent Route Optimizer application for vehicle 3.

\begin{tabular}{ccccccc}
\hline Location Name & $\begin{array}{c}\text { Distance } \\
(\text { Before) } \mathbf{( k m )}\end{array}$ & $\begin{array}{c}\text { Distance } \\
(\mathbf{A f t e r}) \mathbf{( k m )}\end{array}$ & $\begin{array}{c}\text { Reduction in } \\
\text { Distance } \mathbf{( k m )}\end{array}$ & $\begin{array}{c}\text { Time (Before) } \\
\mathbf{( m i n )}\end{array}$ & $\begin{array}{c}\text { Time (After) } \\
\mathbf{( m i n )}\end{array}$ & $\begin{array}{c}\text { Reduction in } \\
\text { Time } \mathbf{( m i n )}\end{array}$ \\
\hline Depot & 0.0 & 0.0 & 0.0 & 0.0 & 0.0 & 0.0 \\
Outlet 16 & 6.4 & 6.1 & 0.3 & 31.0 & 28.0 & 3.0 \\
Outlet 18 & 2.1 & 1.6 & 0.5 & 12.0 & 9.0 & 3.0 \\
Outlet 17 & 1.2 & 1.0 & 0.2 & 23.0 & 20.0 & 3.0 \\
Outlet 20 & 3.4 & 3.0 & 0.4 & 42.0 & 38.0 & 4.0 \\
Depot & 7.0 & 7.0 & 0.0 & & & \\
\hline
\end{tabular}

Table 6. Traveling distance before and after using the Intelligent Route Optimizer application for vehicle 4.

\begin{tabular}{|c|c|c|c|c|c|c|}
\hline Location Name & $\begin{array}{c}\text { Distance } \\
\text { (Before) }(\mathbf{k m})\end{array}$ & $\begin{array}{c}\text { Distance } \\
\text { (After) (km) }\end{array}$ & $\begin{array}{l}\text { Reduction in } \\
\text { Distance }(\mathbf{k m})\end{array}$ & $\begin{array}{c}\text { Time (Before) } \\
\text { (min) }\end{array}$ & $\begin{array}{c}\text { Time (After) } \\
\text { (min) }\end{array}$ & $\begin{array}{l}\text { Reduction in } \\
\text { Time (min) }\end{array}$ \\
\hline Depot & 0.0 & 0.0 & 0.0 & 0.0 & 0.0 & 0.0 \\
\hline Outlet 11 & 6.5 & 6.1 & 0.4 & 34.0 & 30.0 & 4.0 \\
\hline Outlet 14 & 4.2 & 3.4 & 0.8 & 20.0 & 15.0 & 5.0 \\
\hline Outlet 12 & 4.1 & 3.1 & 1.0 & 21.0 & 15.0 & 6.0 \\
\hline Outlet 13 & 3.0 & 2.4 & 0.6 & 15.0 & 13.0 & 2.0 \\
\hline Outlet 15 & 4.1 & 3.0 & 1.1 & 26.0 & 21.0 & 5.0 \\
\hline Outlet 19 & 4.0 & 3.6 & 0.4 & 30.0 & 27.0 & 3.0 \\
\hline Depot & 4.2 & 3.8 & 0.4 & 31.0 & 25.0 & 6.0 \\
\hline
\end{tabular}

Figure 11 shows the vehicle-wise traveled distance and time before and after implementing the intelligent route optimizer. It was observed that the traveled distance for vehicle 1, vehicle 2, vehicle 3 and vehicle 4 are reduced by $3.6 \mathrm{~km}, 2.1 \mathrm{~km}, 1.4 \mathrm{~km}$, and $4.7 \mathrm{~km}$, respectively. Moreover, the traveled time is reduced for vehicle 1, vehicle 2, vehicle 3 and vehicle 4 are $35 \mathrm{~min}, 35 \mathrm{~min}, 13 \mathrm{~min}$, and $31 \mathrm{~min}$, respectively. In this instance, Figure 12a provides valuable information of traveled time with distance before and after implementing the intelligent route optimizer. The travel time and distance follow similar behavior as observed [76] with empirical results of road transportation. 


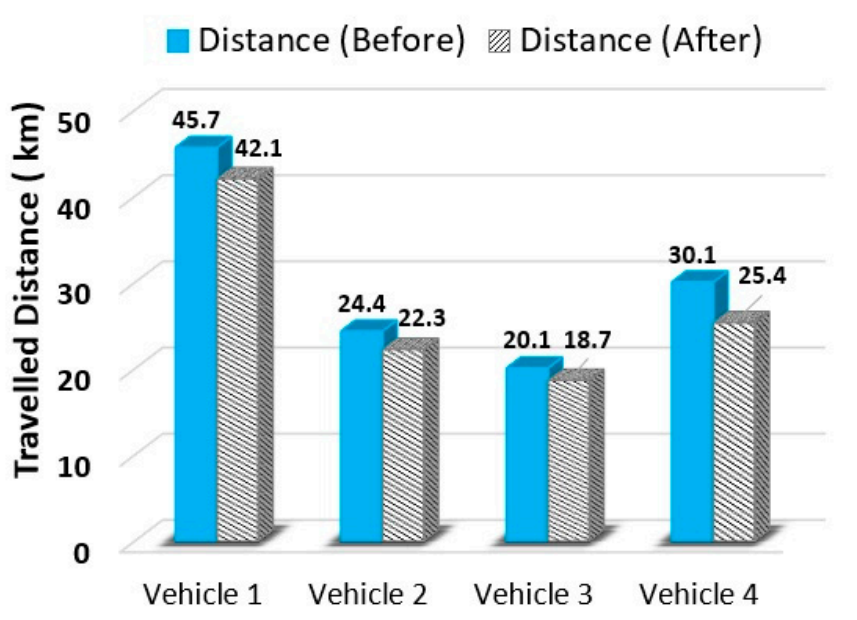

Vehicle

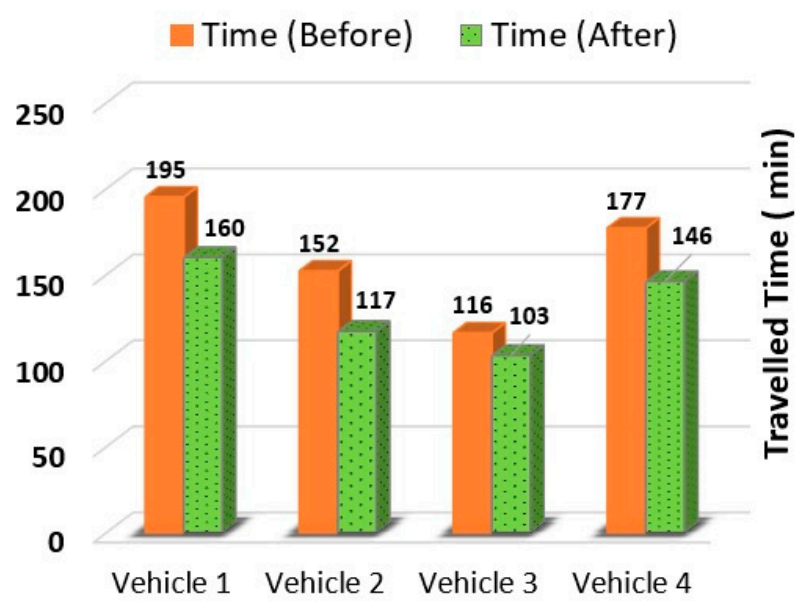

Vehicle

Figure 11. Comparison of total traveling distance and time.

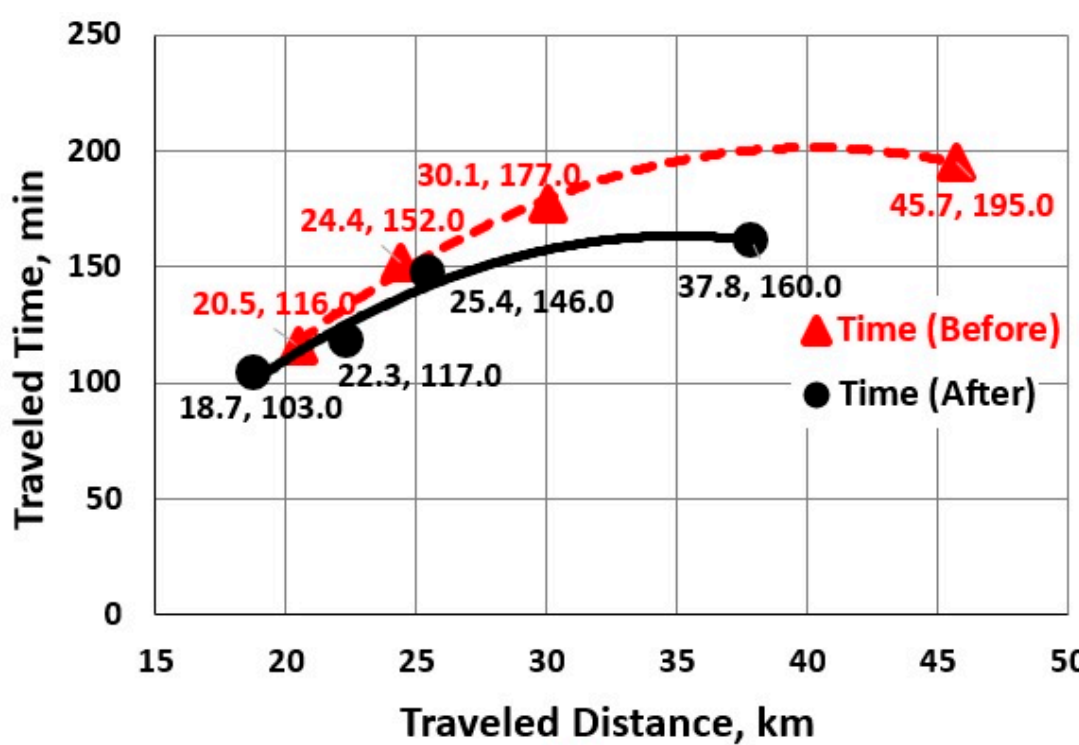

(a)

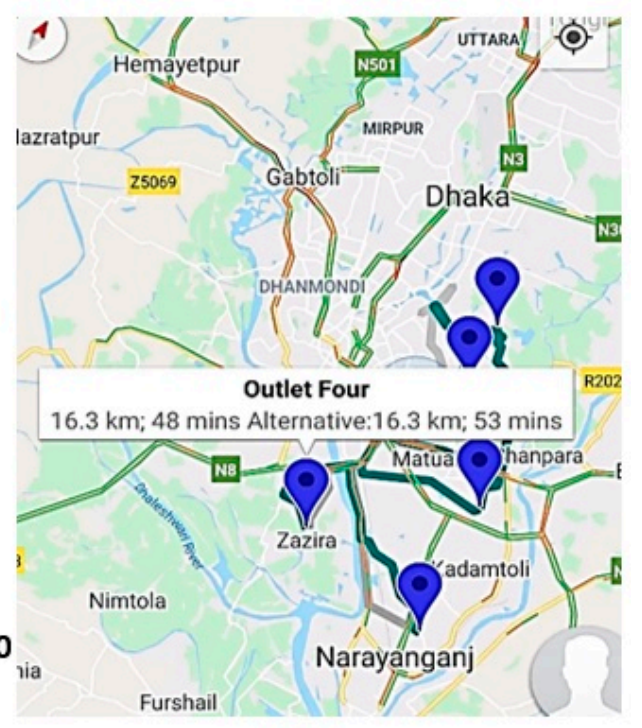

(b)

Figure 12. (a) Empirical relationship between traveled distance and time before and after using the intelligent routing optimizer (b) non-linear correlation of distance and time showing optimum routing $(16.3 \mathrm{~km}, 48 \mathrm{~min})$ and alternate routing $(16.3 \mathrm{~km}, 53 \mathrm{~min})$.

Additionally, a non-linear relationship between traveling distance and time is evident from Figure 12b, where the optimal route suggests $16.3 \mathrm{~km}$ in $48 \mathrm{~min}$ and the alternate route suggests $16.3 \mathrm{~km}$ in $53 \mathrm{~min}$ to reach the destination. The traveling distance was the same $(16.3 \mathrm{~km})$, but an increased time is shown for the alternate routing. This could be due to the effect of real-time road traffic conditions considered in the intelligent routing optimizer.

A noticeable improvement of traveled distance and time for the individual vehicle was observed using the developed application on the journey, as illustrated in Figure 13a. This is evident from the juxtaposition of the percent reduction of distance and time for non-optimal (without the application) and optimal (with the application) for each vehicle.

Additionally, percent reduction data of distance and time for Region 1 and Region 2, shown in Figure 13b, suggests a substantial improvement in each region before and after using the intelligent routing optimizer. The non-proportionality relationship between percent reduction of distance and time is observed in Figure 13. This could be due to the inclusion of non-driving time into the total travel time arising from the influence of traffic obstacles, traffic signals, and jams in the Dhaka city road network [58]. Moreover, higher 
values of the percent reduction in Region 1 than in Region 2 support the effect of new and extended road networks on transportation in Region 1 of Dhaka city [59]. Therefore, improved road traffic conditions and network infrastructure augment better vehicle routing results with Intelligent Routing Optimization.

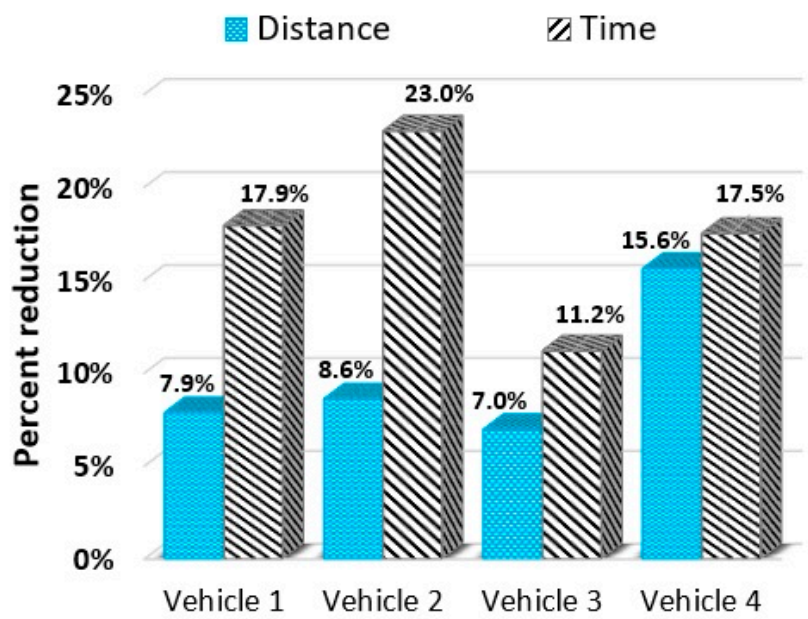

(a) Vehicle

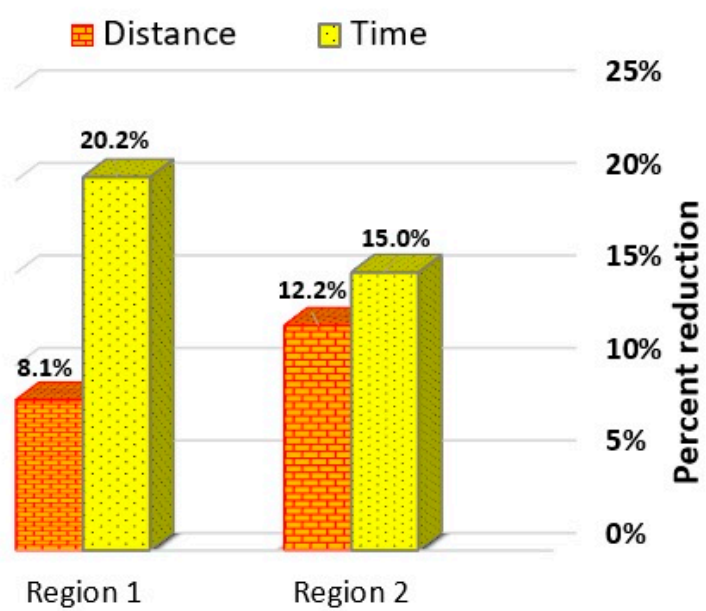

(b) Region

Figure 13. Percent reductions of distance and time for (a) each individual vehicle; (b) each region.

\section{Conclusions}

In this study, intelligent vehicle routing is demonstrated for a chain of retail stores using the demand information of different outlets, combining those demands and clustering these by territory. The Google Sheet-based scheduling and navigation plans were developed by using those clustered territories. Finally, an Android Studio 4.0 based application was developed by incorporating artificial intelligence to respond to the real-time traffic data for vehicle routing. The following conclusions can be drawn from this research:

- An optimization approach was applied to design vehicle scheduling and to find the shortest path between nodes (outlets/stores). Based on real-time traffic data, the application generates an alternate shortest path to avoid any obstruction during the journey, where several outlets are to be visited in a single journey.

- The spreadsheet-based solver tool utilizing the Google Vehicle Routing add-on improves the vehicle scheduling and navigation sequence. This is due to the use of Google Maps and the consideration of real-time traffic conditions during the scheduling process. Moreover, the application was developed based on real-time traffic information, expecting an optimum vehicle routing solution.

- The application displays the shortest route with an alternative best route to the destination. The 'On Map Tap' feature underpins the uniqueness of the application, as it generates the path once the location is tapped, compared to other VRP applications where the destination and location have to be selected manually. Using the intelligent route optimizer application, both the traveling time and distances are decreased in the journey. Sometimes the path may be shortest, but it may take longer than the other routes due to traffic conditions on the road. Thus, the application not only considers the distance but also suggests the shortest time to reach the outlet to achieve an optimal routing solution.

\section{Limitations and Future Research Directions}

This paper presents a numerical example of demand fulfillment of a retail chain store with four vehicles of a 24-ton capacity. Moreover, the study considers rice and pulse only, while a grocery chain deals with many other products. This model can be extended for multiple outlets with larger shipments and more vehicles, as experienced by a retail chain 
in real life. However, that would generate similar results on a greater scale with a bit of addition to the managerial insights. In this research, traveling routes between two nodes were optimized following the Dijkstra algorithm. The current study assumed that one node is served by one vehicle only. Serving one outlet by two or more vehicles will be an interesting case for further research. In future works, the logistics networks can be improved by sequencing and optimizing all nodes simultaneously based on the real-time traffic. Furthermore, the application of other algorithms such as Bellman-Ford Algorithm and the Floyd-Warshall Algorithm can also be explored. The study can be further enhanced by incorporating the effect of transportation-related factors such as peak and off-peak time, vehicle condition, vehicle speed, transport idle time in the signals, and road/network conditions on the intelligent vehicle routing optimization. This is expected to significantly improve the distribution plan for a chain of retail stores by utilizing the application for the whole delivery system.

Author Contributions: Conceptualization, M.A.R., A.-A.H., B.D. and Z.M.Z.; Data curation, A.A.H. and B.D.; Formal analysis, M.A.R., B.D. and Z.H.A.; Investigation, A.-A.H., B.D. and Z.M.Z.; Methodology, M.A.R., A.-A.H., B.D. and Z.M.Z.; Resources, M.A.R. and M.S.M.; Software, A.-A.H., B.D. and Z.M.Z.; Supervision, M.A.R.; Validation, A.-A.H. and B.D.; Writing-original draft, M.A.R., A.-A.H., B.D. and Z.H.A.; Writing-review \& editing, M.A.R., M.S.M. and Z.H.A. All authors have read and agreed to the published version of the manuscript.

Funding: This research received no external funding.

Institutional Review Board Statement: Not applicable.

Informed Consent Statement: Not applicable.

Data Availability Statement: All data is included in the manuscript.

Acknowledgments: Department of Mechanical and Production Engineering, Ahsanullah University of Science and Technology, Dhaka, Bangladesh. Authors are delightedly thankful to Elias Parvez, head of operations, for providing the delivery data and Sumon Islam for assisting the programming during the application development.

Conflicts of Interest: The authors declare no conflict of interest.

\section{References}

1. Ponis, S.T.; Efthymiou, O.K. Cloud and IoT applications in material handling automation and intralogistics. Logistics 2020, 4, 22. [CrossRef]

2. Zouari, D.; Ruel, S.; Viale, L. Does digitalising the supply chain contribute to its resilience? Int. J. Phys. Distrib. Logist. Manag. 2021, 51, 149-180. [CrossRef]

3. Colli, M.; Berger, U.; Bockholt, M.; Madsen, O.; Møller, C.; Wæhrens, B.V. A maturity assessment approach for conceiving context-specific roadmaps in the Industry 4.0 era. Annu. Rev. Control. 2019, 48, 165-177. [CrossRef]

4. Büyüközkan, G.; Göçer, F. Digital Supply Chain: Literature review and a proposed framework for future research. Comput. Ind. 2018, 97, 157-177. [CrossRef]

5. Díaz-Madroñero, M.; Peidro, D.; Mula, J. A review of tactical optimization models for integrated production and transport routing planning decisions. Comput. Ind. Eng. 2015, 88, 518-535. [CrossRef]

6. Brekalo, L.; Albers, S. Effective logistics alliance design and management. Int. J. Phys. Distrib. Logist. Manag. 2016, 46, 212-240. [CrossRef]

7. Chopra, S.; Meindl, P.; Kalra, D.V. Supply Chain Management: Strategy, Planning, and Operation; Pearson: Boston, MA, USA, 2013; pp. 13-25.

8. Coyle, J.J.; Langley, C.J.; Novack, R.A.; Gibson, B. Supply Chain Management: A Logistics Perspective; Cengage Learning: Boston, MA, USA, 2016; pp. 51-77.

9. Teodorovic, D.; Lucic, P. Intelligent vehicle routing system. In Proceedings of the IEEE Conference on Intelligent Transportation Systems ITSC2000, Dearborn, MI, USA, 1-3 October 2000; pp. 482-487. [CrossRef]

10. Abosuliman, S.S.; Almagrabi, A.O. Routing and scheduling of intelligent autonomous vehicles in industrial logistics systems. Soft Comput. 2021, 25, 11975-11988. [CrossRef]

11. Liu, J.; Mirchandani, P.; Zhou, X. Integrated vehicle assignment and routing for system-optimal shared mobility planning with endogenous road congestion. Transp. Res. C Emerg. Technol. 2020, 117, 102675. [CrossRef] 
12. Lin, C.H.; Yu, J.L.; Liu, J.C.; Lee, C.J. Genetic algorithm for shortest driving time in intelligent transportation systems. In Proceedings of the 2008 International Conference on Multimedia and Ubiquitous Engineering (MUE 2008), Busan, Korea, 24-26 April 2008; pp. 402-406.

13. Ericsson, E.; Larsson, H.; Brundell-Freij, K. Optimizing route choice for lowest fuel consumption-Potential effects of a new driver support tool. Transp. Res. C Emerg. Technol. 2006, 14, 369-383. [CrossRef]

14. Azmat, M.; Kummer, S.; Moura, L.T.; Gennaro, F.D.; Moser, R. Future outlook of highway operations with implementation of innovative technologies like AV, CV, IoT and Big Data. Logistics 2019, 3, 15. [CrossRef]

15. Prasse, C.; Nettstraeter, A.; Hompel, M.T. How IoT will change the design and operation of logistics systems. In Proceedings of the 2014 International Conference on the Internet of Things (IOT), Cambridge, MA, USA, 6-8 October 2014; pp. 55-60.

16. Weber, F.D.; Schütte, R. State-of-the-art and adoption of artificial intelligence in retailing. Digit. Policy, Regul. Gov. 2019, 21, 264-279. [CrossRef]

17. Wurman, P.R.; D’Andrea, R.; Mountz, M. Coordinating hundreds of cooperative, autonomous vehicles in warehouses. AI Mag. 2008, 29, 9 .

18. Stevens, L.; Phillips, E.E. Amazon Puzzles over the Perfect Fit-In Boxes. Available online: https://www.wsj.com/articles/ amazon-aims-for-one-box-fits-all-1513765800 (accessed on 17 June 2021).

19. Weber, F.; Schütte, R. A domain-oriented analysis of the impact of machine learning-The case of retailing. Big Data Cogn. Comput. 2019, 3, 11. [CrossRef]

20. Mkansi, M.; de Leeuw, S.; Amosun, O. Mobile application supported urban-township e-grocery distribution. Int. J. Phys. Distrib. Logist. Manag. 2020, 50, 26-53. [CrossRef]

21. Hossain, M.A. Developing Backward Linkage for Supermarket in Bangladesh: An Empirical Study. Ph.D. Thesis, University of Dhaka, Dhaka, Bangladesh, 2017.

22. Ellram, L.M.; La Londe, B.J.; Weber, M.M. Retail logistics. Int. J. Phys. Distrib. Mater. Manag. 1989, 19, 29-39. [CrossRef]

23. Alam, Z.M.; Rana, S.S.M. Customers' attitudes towards retail chain store ser-vices in Bangladesh-A comparative study between retail chain stores and small retail stores. J. Bus. Stud. 2013, 5, 1-18.

24. Takvir, A. Distribution management for a retail chain "Shwapno". Int. J. Sci. Eng. Res. 2018, 9, 431-434.

25. Dantzig, G.B.; Ramser, J.H. The truck dispatching problem. Manag. Sci. 1959, 6, 80-91. [CrossRef]

26. Røpke, S.; Pisinger, D. An adaptive large neighborhood search heuristic for the pickup and delivery problem with time windows. Transp. Sci. 2006, 40, 455-472. [CrossRef]

27. Taniguchi, E.; Shimamoto, H. Intelligent transportation system based dynamic vehicle routing and scheduling with variable travel times. Transp. Res. C Emerg. Technol. 2004, 12, 235-250. [CrossRef]

28. Ghiani, G.; Guerriero, F.; Laporte, G.; Musmanno, R. Real-time vehicle routing: Solution concepts, algorithms and parallel computing strategies. Eur. J. Oper. Res. 2003, 151, 1-11. [CrossRef]

29. Nha, V.T.N.; Djahel, S.; Murphy, J. A comparative study of vehicles' routing algorithms for route planning in smart cities. In Proceedings of the 2012 First International Workshop on Vehicular Traffic Management for Smart Cities (VTM), Dublin, Ireland, 20-20 November 2012. [CrossRef]

30. Dijkstra, E.W. A note on two problems in connexion with graphs. Numer. Math. 1959, 1, 269-271. [CrossRef]

31. Eklund, P.W.; Kirkby, S.; Pollitt, S. Dynamic multi-source Dijkstra's algorithm for vehicle routing. In Proceedings of the 1996 Australian New Zealand Conference on Intelligent Information Systems ANZIIS 96, Adelaide, SA, Australia, 18-20 November 1996; pp. 329-333. [CrossRef]

32. Kaffash, S.; Nguyen, A.T.; Zhu, J. Big data algorithms and applications in intelligent transportation system: A review and bibliometric analysis. Int. J. Prod. Econ. 2021, 231, 107868. [CrossRef]

33. Do, H.N.; Vo, M.; Vuong, B.Q.; Pham, H.T.; Nguyen, A.H.; Luong, H.Q. Automatic license plate recognition using mobile device. In Proceedings of the International Conference on Advanced Technologies for Communications (ATC), Hanoi, Vietnam, 12-14 October 2016; IEEE: Piscataway, NJ, USA, 2016; pp. 268-271.

34. Dong, C.; Akram, A.; Andersson, D.; Arnäs, P.-O.; Stefansson, G. The impact of emerging and disruptive technologies on freight transportation in the digital era: Current state and future trends. Int. J. Logist. Manag. 2021, 32, 386-412. [CrossRef]

35. Schuldt, A.; Hribernik, K.; Gehrke, J.D.; Thoben, K.-D.; Herzog, O. Cloud computing for autonomous control in logistics. In INFORMATIK 2010. Service Science-Neue Perspektiven für die Informatik; Fähnrich, K.-P., Franczyk, B., Eds.; Gesellschaft für Informatik e.V.: Bonn, Germany, 2010; Volume 1, pp. 305-310.

36. Moufaddal, M.; Benghabrit, A.; Bouhaddou, I. A cyber-physical warehouse management system architecture in an Industry 4.0 context. In Advances in Intelligent Systems and Computing, Proceedings of the Artificial Intelligence and Industrial Applications. A2IA 2020, Meknes, Morocco, 4-5 December 2020; Masrour, T., Cherrafi, A., El Hassani, I., Eds.; Springer: Cham, Switzerland, 2021; Volume 1193. [CrossRef]

37. Rawat, D.B.; Bajracharya, C. An overview of vehicular networking and cyber-physical systems. In Vehicular Cyber Physical Systems; Springer: Cham, Switzerland, 2017; Chapter 1; pp. 1-13. [CrossRef]

38. Erdoğan, G. An open source spreadsheet solver for vehicle routing problems. Comput. Oper. Res. 2017, 84, 62-72. [CrossRef]

39. Azab, A.; Park, J.; Mostafa, N.A. Smart mobile application for short-haul cargo transportation. Logistics 2021, 5, 36. [CrossRef]

40. Zeng, W.; Church, R.L. Finding shortest paths on real road networks: The case for A*. Int. J. Geogr. Inf. Sci. 2009, 23, 531-543. [CrossRef] 
41. Gallo, G.; Pallottino, S. A new algorithm to find the shortest paths between all pairs of nodes. Discret. Appl. Math. 1982, 4, 23-35. [CrossRef]

42. Pallottino, S. Shortest-path methods: Complexity, interrelations and new propositions. Networks 1984, 14, 257-267. [CrossRef]

43. Khantanapoka, K.; Chinnasarn, K. Pathfinding of 2D \& 3D game real-time strategy with Depth Direction A* algorithm for multi-layer. In Proceedings of the Eighth International Symposium on Natural Language Processing, Bangkok, Thailand, 20-22 October 2009; pp. 184-188. [CrossRef]

44. Nuanmeesri, S. Mobile application for the purpose of marketing, product distribution and location-based logistics for elderly farmers. Appl. Comput. Inform. 2019. [CrossRef]

45. Ky Phuc, P.N.; Phuong Thao, N.L. Ant colony optimization for multiple pickup and multiple delivery vehicle routing problem with time window and heterogeneous fleets. Logistics 2021, 5, 28. [CrossRef]

46. Shi, H.; Sun, L.; Teng, Y.; Hu, X. An online intelligent vehicle routing and scheduling approach for B2C e-commerce urban logistics distribution. Procedia Comput. Sci. 2019, 159, 2533-2542. [CrossRef]

47. Chmiel, W.; Skalna, I.; Jędrusik, S. Intelligent route planning system based on interval computing. Multimedia Tools Appl. 2018, 78, 4693-4721. [CrossRef]

48. Ahmadullah, N.; Islam, S.; Ahmed, T. Route Finder: Real-time optimum vehicle routing using mobile phone network. In Proceedings of the TENCON 2015-2015 IEEE Region 10 Conference, Macao, China, 1-4 November 2015; pp. 1-7. [CrossRef]

49. Kikelomo, A.A.; Asafe, Y.N.; Paul, A.; Olawale, L.N. Design and implementation of mobile map application for finding shortest direction between two pair locations using shortest path algorithm: A case study. Int. J. Adv. Netw. Appl. 2017, 9, $3300-3305$.

50. Zunic, E.; Hindija, H.; Besirevic, A.; Hodzic, K.; Delalic, S. Improving performance of vehicle routing algorithms using GPS data. In Proceedings of the 14th Symposium on Neural Networks and Applications (NEUREL), Belgrade, Serbia, 20-21 November 2018; pp. 1-4. [CrossRef]

51. Jose, D.; Prasad, S.; Sridhar, V. Intelligent vehicle monitoring using global positioning system and cloud computing. Procedia Comput. Sci. 2015, 50, 440-446. [CrossRef]

52. Li, R.; Cheng, C.; Qi, M.; Lai, W. Design of dynamic vehicle routing system based on online map service. In Proceedings of the 2016 13th International Conference on Service Systems and Service Management (ICSSSM), Kunming, China, 24-26 June 2016; pp. 1-5. [CrossRef]

53. Zambrano-Vega, C.; Acosta, G.; Loor, J.; Suárez, B.; Jaramillo, C.; Oviedo, B. A sales route optimization mobile application applying a genetic algorithm and the Google Maps navigation system. In Proceedings of the Information Technology and Systems. ICITS 2019, Quito, Ecuador, 6-8 February 2019; Rocha, Á., Ferrás, C., Paredes, M., Eds.; Advances in Intelligent Systems and Computing. Springer: Cham, Switzerland, 2019; Volume 918, pp. 517-527. [CrossRef]

54. Pfoser, D.; Efentakis, A.; Wenk, C. Exploiting Road Network Properties in Effiient Shortest-Path Computation; International Computer Science Institute: Berkley, CA, USA, 2009; Available online: http:/ /www.icsi.berkeley.edu/pubs/techreports/TR-09-007.pdf (accessed on 9 August 2021).

55. Shahrier, M.; Hasnat, A. Route optimization issues and initiatives in Bangladesh: The context of regional significance. Transp. Eng. 2021, 4, 100054. [CrossRef]

56. Gregor, T.; Krajčovič, M.; Więcek, D. Smart connected logistics. Procedia Eng. 2017, 192, 265-270. [CrossRef]

57. Corner, R.J.; Dewan, A.M. Introduction in Dhaka Megacity: Geospatial Perspectives on Urbanisation, Environment and Health; Springer: New York, NY, USA, 2014; pp. 1-22.

58. Khan, S.M.; Hoque, M.S. Traffic flow interruptions in Dhaka city: Is smooth traffic flow possible? J. Precidency Univ. 2013, 2, 46-54.

59. Swapan, M.S.H.; Zaman, A.U.; Ahsan, T.; Ahmed, F. Transforming urban dichotomies and challenges of South Asian megacities: Rethinking sustainable growth of Dhaka, Bangladesh. Urban Sci. 2017, 1, 31. [CrossRef]

60. Islam, S. Banglapedia-The National Encyclopedia of Bangladesh; Dhaka City Corporation: Dhaka, Bangladesh, 2012.

61. Zagetdoo. Available online: https:/ / www.zagetdoo.com/vehicle-routing (accessed on 4 June 2021).

62. Maciejewski, M.; Bischoff, J.; Hörl, S.; Nagel, K. Towards a testbed for dynamic vehicle routing algorithms. In Proceedings of the Highlights of Practical Applications of Cyber-Physical Multi-Agent Systems, PAAMS 2017, Porto, Portugal, 21-23 June 2017; Bajo, J., Vale, Z., Hallenborg, K., Rocha, A.P., Mathieu, P., Pawlewski, P., Del Val, E., Novais, P., Lopes, F., Duque Méndez, N.D., et al., Eds.; Communications in Computer and Information Science. Springer: Cham, Switzerland, 2017 ; Volume 722. [CrossRef]

63. Debnath, B.; Hossain, A.; Zefat, Z.M.; Rahman, M.A. An intelligent approach of vehicle routing of Super Shop Shawpno. In Proceedings of the International Conference on Mechanical, Industrial and Energy Engineering (ICMIE), Khulna, Bangladesh, 19-21 December 2020.

64. Barceló, J.; Grzybowska, H.; Pardo, S. Vehicle routing and scheduling models, simulation and city logistics. In Dynamic Fleet Management; Zeimpekis, V., Tarantilis, C.D., Giaglis, G.M., Minis, I., Eds.; Operations Research/Computer Science Interfaces Series; Springer: Boston, MA, USA, 2007; Volume 38. [CrossRef]

65. Suresh, S.; Renukappa, S.; Abdul-Aziz, A.-R.; Paloo, Y.; Jallow, H. Developments in the UK road transport from a smart cities perspective. Eng. Constr. Arch. Manag. 2021, 28, 845-862. [CrossRef]

66. Di Nardo, M. Developing a conceptual framework model of Industry 4.0 for industrial management. Ind. Eng. Manag. Syst. 2020, 19, 551-560. [CrossRef] 
67. Nardo, M.; Forino, D.; Murino, T. The evolution of man-machine interaction: The role of human in Industry 4.0 paradigm. Prod. Manuf. Res. 2020, 8, 20-34. [CrossRef]

68. Global Mobile App Revenue 2021. Available online: https:/ /www.statista.com/statistics/269024/ (accessed on 26 May 2021).

69. Holzer, A.; Ondrus, J. Trends in mobile application development. In Proceedings of the Mobile Wireless Middleware, Operating Systems, and Applications-Workshops, MOBILWARE 2009, Berlin, Germany, 28-29 April 2009; Hesselman, C., Giannelli, C., Eds.; Lecture Notes of the Institute for Computer Sciences, Social Informatics and Telecommunications Engineering. Springer: Berlin/Heidelberg, Germany, 2009; Volume 12. [CrossRef]

70. Pon, B.; Seppälä, T.; Kenney, M. Android and the demise of operating system-based power: Firm strategy and platform control in the post-PC world. Telecommun. Policy 2014, 38, 979-991. [CrossRef]

71. Gandhewar, N.; Sheikh, R. Google Android: An Emerging Software Platform for Mobile Devices. Available online: https: / / citeseerx.ist.psu.edu/viewdoc/download?doi=10.1.1.637.3019\&rep=rep1\&type=pdf (accessed on 9 August 2021).

72. Morón, M.J.; Luque, R.; Casilari, E. On the capability of smartphones to perform as communication gateways in medical wireless personal area networks. Sensors 2014, 14, 575-594. [CrossRef]

73. Android Studio. Available online: https://developer.android.com/studio (accessed on 26 May 2021).

74. Cormen, T.H.; Leiserson, C.E.; Rivest, R.L.; Stein, C. Introduction to Algorithms, 2nd ed.; The MIT Press: Cambridge, MA, USA, 2001.

75. Geographic Information Technology Training Alliance. Available online: http://www.gitta.info/Accessibiliti/en/html/Dijkstra_ learningObject1.html (accessed on 18 June 2021).

76. Rietveld, P.; Zwart, B.; van Wee, B.; Hoorn, T.V.D. On the relationship between travel time and travel distance of commuters. Ann. Reg. Sci. 1999, 33, 269-287. [CrossRef] 